\title{
Non-isothermal modelling of the all-vanadium redox flow battery
}

\author{
H. Al-Fetlawi, A.A. Shah*, F.C. Walsh \\ Energy Technology Research Group, School of Engineering Sciences, University of Southampton, Highfields, Southampton SO17 1BJ, United Kingdom
}

\section{A R T I C L E I N F O}

\section{Article history:}

Received 23 May 2009

Received in revised form 8 August 2009

Accepted 9 August 2009

Available online 18 August 2009

\section{Redox flow battery}

Vanadium

Modelling and simulation

Energy balance

Temperature

\begin{abstract}
A B S T R A C T
An non-isothermal model for the all-vanadium redox flow battery (RFB) is presented. The twodimensional model is based on a comprehensive description of mass, charge, energy and momentum transport and conservation, and is combined with a global kinetic model for reactions involving vanadium species. Heat is generated as a result of activation losses, electrochemical reaction and ohmic resistance. Numerical simulations demonstrate the effects of changes in the operating temperature on performance. It is shown that variations in the electrolyte flow rate and the magnitude of the applied current substantially alter the charge/discharge characteristics, the temperature rise and the distribution of temperature. The influence of heat losses on the charge/discharge behaviour and temperature distribution is investigated. Conditions for localised heating and membrane degradation are discussed.
\end{abstract}

(c) 2009 Elsevier Ltd. All rights reserved.

\section{Introduction}

Energy storage technologies will play a crucial role in the future delivery of efficient and renewable energy sources such as wind and solar, which typically suffer from intermittency problems. One of the most promising of these technologies is the redox flow battery (RFB), as a candidate for medium- and large-scale energy storage solutions. RFBs store energy in solutions containing different redox couples and the reversible electrode processes take place at the surfaces of inert or catalysed electrodes that can be either porous or non-porous. The reactants flowing across the electrodes enter from reservoirs external to the electrochemical cell and the electrolytes in the two compartments are prevented from mixing in the electrochemical cell by an ion-selective membrane or micro-porous separator. In theory, the capacity of the system is determined by the volume of the electrolyte tanks, while the system power is determined by the size of the stacks and the active electrode surface area. There are a number of potential applications of RFBs, notably load levelling and peak shaving, uninterruptible power supplies, emergency backup and the aforementioned facilitation of wind and photovoltaic energy delivery [1,2].

RFB technology compares favourably with established technologies such as static lead-acid batteries [1,3]. RFB cells can achieve high energy efficiencies (between $80 \%$ and $90 \%$ in large installations at a low cost per $\mathrm{kWh}$ ), they have a long cycle life, they are relatively easily maintained and can be fully discharged without harm

\footnotetext{
* Corresponding author. Tel.: +44 0238059 8520; fax: +44 02380593131 .

E-mail address: A.Shah@soton.ac.uk (A.A. Shah).
}

to the battery. Existing RFB systems can be readily upgraded and additional storage capacity easily installed by changing the tanks and volumes of electrolyte. Moreover, the technology does not rely on precious or heavy metals such as platinum, lead, nickel, zinc and cadmium.

Several RFB variants are under development, each employing different redox couples. The all-vanadium cell is one of the most developed $[1,4-6]$ and has been successfully piloted by commercial developers including VRB Power Systems and Sumitomo Electric Industries/Kansai Electric. In order to realise the commercial potential of RFB technology, a number of challenges must be overcome, notably scale-up and optimisation (with respect to flow geometries and operating conditions for example), improvement in electrolyte stability, development of electrode materials resistant to oxidation and mitigation of membrane degradation. Modelling and simulation are cost-effective methods for reducing the costs and long timescales associated with laboratory-based research. Suitably validated tools can be used to inform cell testing programmes, aid optimisation and cell design, and, moreover, provide insight into the fundamental processes inside a working cell. In contrast to conventional batteries such as the lead-acid and lithium-ion [7-12] and fuel cells [13-16], there are few examples RFB modelling. A transient, two-dimensional model based on conservation principles, incorporating the fundamental modes of transport and a kinetic model for reactions involving vanadium species, was developed in [17] for the all-vanadium RFB. The model was validated against experimental data at different flow rates and reactant concentrations. In this paper, the model is extended to include an energy balance, fully coupled to the conservation laws of mass, charge and momentum. Heating by activation losses, electrochemical reaction and ohmic resistance are incorporated. Simulations 
Table 1

Default values of the constants related to structure.

\begin{tabular}{lll}
\hline Symbol & Quantity & Size \\
\hline$h$ & Electrode height & $10 \mathrm{~cm}$ \\
$L_{t}$ & Carbon electrode thickness & $4 \mathrm{~mm}$ \\
$L_{w}$ & Carbon electrode width & $10 \mathrm{~cm}$ \\
$L_{m}$ & Membrane thickness & $200 \mu \mathrm{m}$ \\
$L_{c}$ & Collector thickness & $6.3 \mathrm{~mm}$ \\
$\epsilon$ & Carbon electrode porosity $^{\text {a }}$ & 0.68 \\
$d$ & Carbon electrode mean pore diameter $^{\text {b }}$ & $10 \mu \mathrm{m}$ \\
$L_{w}$ & Electrode width & $10 \mathrm{~cm}$ \\
$V_{T}$ & Electrolyte volume (half-cell) & $250 \mathrm{~mL}$ \\
$a$ & Specific surface area: electrode ${ }^{\text {b }}$ & $2 \times 10^{6} \mathrm{~m}^{-1}$ \\
\hline a Measured. & & \\
b Estimated. & &
\end{tabular}

are performed to study the effects of temperature variations on the charge/discharge characteristics of the cell. The roles played by heat losses, the electrolyte flow rate and the magnitude of the applied current on the charge/discharge behaviour and the distribution of temperature are investigated. The implications of localised heating and membrane degradation are discussed.

In the next section, models for the transport problem and the reaction kinetics are presented, together with initial-boundary conditions and the underlying assumptions. In Section 3, the simulation results are presented and discussed, and in Section 4 the results are summarised.

\section{Model assumptions and equations}

The kinetics associated with reduction and oxidation of vanadium species are known to be highly complex $[18,19]$. In this paper, a simplified set of half-reactions is adopted:

Negative electrode $: \mathrm{V}(\mathrm{III})+\mathrm{e}^{-} \rightleftharpoons \mathrm{V}(\mathrm{II})$

Positive electrode : $\mathrm{VO}^{2+}+\mathrm{H}_{2} \mathrm{O} \rightleftharpoons \mathrm{VO}_{2}^{+}+2 \mathrm{H}^{+}+\mathrm{e}^{-}$

The model is based on a two-dimensional slice, as shown in Fig. 1, which includes the current collectors, electrodes, membrane and reservoirs. The two-dimensional approximation leads to a considerable saving in computational time without a major loss in accuracy if the electrolyte flow rate is reasonably high, which corresponds to normal operation. The structural property values used in the simulations are given in Table 1.

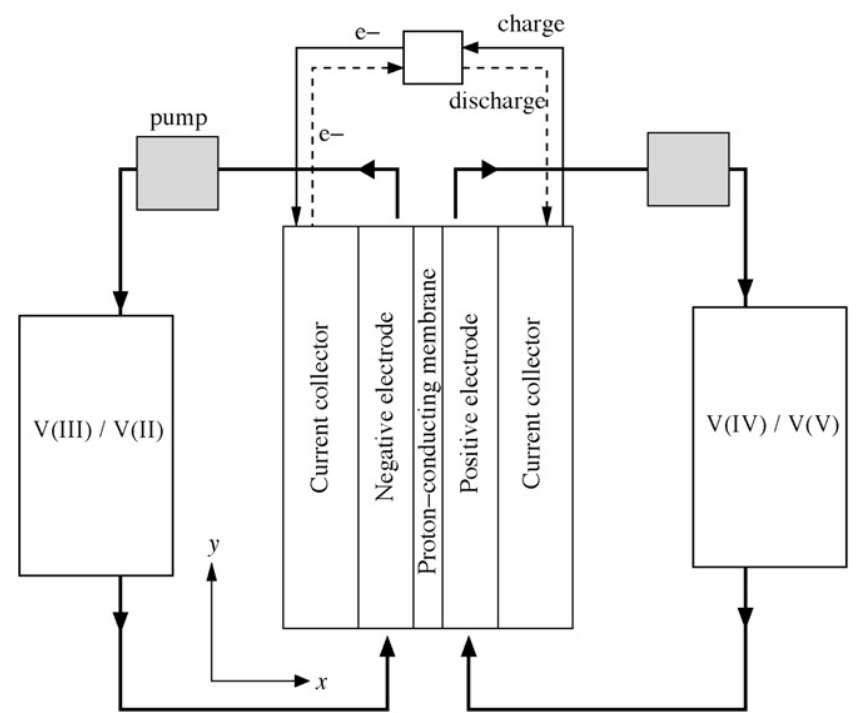

Fig. 1. A schematic of the all-vanadium battery and of the components modelled in this paper: current collectors, porous carbon electrodes, membrane and reservoirs.
Two approximations are made regarding the fluid flow: (i) the dilute-solution approximation; and (ii) incompressible flow. Both of these approximations can be justified by the fact that the bulk of the liquid is water. The volume change resulting from a transfer of water between the electrodes through the membrane is neglected. For calculations over very long times these changes would need to be incorporated but on the timescales considered in the present study the transfer is of the order of one or two percent, and, therefore, does not have a major impact on performance. Proton and water transport in the ion-selective membrane is based on the model of Bernadi and Verbrugge for liquid-saturated membranes $[20,21]$. To conserve space, the model is presented in an attenuated form; the reader is referred to [17] for full details of the equations.

\subsection{Principles of conservation}

The electrolyte solutions are considered to be made from water, $\mathrm{H}_{2} \mathrm{SO}_{4}$ (dissociated in the water) and soluble vanadium species. The species considered are $\mathrm{V}(\mathrm{II}), \mathrm{V}(\mathrm{III}), \mathrm{V}(\mathrm{IV}), \mathrm{V}(\mathrm{V}), \mathrm{H}_{2}, \mathrm{H}^{+}, \mathrm{HSO}_{4}{ }^{-}$ and $\mathrm{SO}_{4}{ }^{2-}$. For each species, a mass balance in the porous regions, using the Nernst-Planck equation for the flux, yields the following equation for each species $i$ :

$\frac{\partial}{\partial t}\left(\epsilon c_{i}\right)+\nabla \cdot\left(-\epsilon^{3 / 2} D_{i} \nabla c_{i}-\frac{z_{i} c_{i} \epsilon^{3 / 2} D_{i}}{R T} F \nabla \phi+\vec{v} c_{i}\right)=-S_{i}$

where $\epsilon$ is the electrode porosity, $S_{i}$ is the source term for species $i$ (defined in Table 2), $\vec{v}$ is the superficial electrolyte velocity, $\phi$ is the ionic potential, and $D_{i}$ and $z_{i}$ are the free space diffusion coefficient and charge of species $i$, respectively, and $F$ is Faraday's constant. Note that the subscripts $i=2,3,4$ and 5 are used to denote quantities associated with $\mathrm{V}(\mathrm{II}), \mathrm{V}(\mathrm{III}), \mathrm{V}(\mathrm{IV})$ and $\mathrm{V}(\mathrm{V})$, respectively. The velocity $\vec{v}$ is given by Darcy's law:

$\vec{v}=-\frac{d^{2}}{K \mu} \frac{\epsilon^{3}}{(1-\epsilon)^{2}} \nabla p$

where $p$ is the liquid pressure, $\mu$ is the dynamic viscosity of the liquid, $d$ is a mean pore diameter and $K$ is the Kozeny-Carman constant for a fibrous medium [22] (the electrode is typically a porous carbon foam such as Sigratherm ${ }^{\circledR}$ GFA5). The transport property values used in the simulations are listed in Table 3.

The concentration of $\mathrm{SO}_{4}{ }^{2-}$ can be determined from the condition of electroneutrality $\sum_{i} z_{i} c_{i}=0$. The total current density in the electrolyte, $\vec{j}$, satisfies [23]:

$\vec{j}=-\sigma_{e}^{\text {eff }} \nabla \phi-F \sum_{i} z_{i} \epsilon^{3 / 2} D_{i} \nabla c_{i}$

in which $\sigma_{e}^{\text {eff }}$ is the effective electrolyte conductivity:

$\sigma_{e}^{\text {eff }}=\frac{F^{2}}{R T} \sum_{i} z_{i}^{2} \epsilon^{3 / 2} D_{i} c_{i}$

$T(x, y, t)$ is the local temperature of the system and $R$ is the molar gas constant.

Table 2

Sources and sinks for the liquid phase Eq. (3).

\begin{tabular}{lll}
\hline Source term & $\begin{array}{l}\text { Positive } \\
\text { electrode }\end{array}$ & $\begin{array}{l}\text { Negative } \\
\text { electrode }\end{array}$ \\
\hline$S_{2}$ (V(II) concentration equation) & - & $\nabla \cdot \vec{j}_{1} / F$ \\
$S_{3}$ (V(III) concentration equation) & - & $-\nabla \cdot \vec{j}_{1} / F$ \\
$S_{4}$ (V(IV) concentration equation) & $\nabla \cdot \vec{j}_{2} / F$ & - \\
$S_{5}$ (V(V) concentration equation) & $-\nabla \cdot \vec{j}_{2} / F$ & - \\
$S_{\mathrm{H}_{2} \mathrm{O}}$ (water concentration equation) & $\nabla \cdot \vec{j}_{2} / F$ & - \\
$S_{\mathrm{H}^{+}}$(proton concentration equation) & - & $-2 \nabla \cdot$ \\
& & $\vec{j}_{2} / F$ \\
\hline
\end{tabular}


Table 3

Default values for constants related to the transport of charge and mass.

\begin{tabular}{|c|c|c|}
\hline Symbol & Quantity & Size \\
\hline$D_{2}$ & $\begin{array}{l}\text { V(II) diffusion coefficient in } \\
\text { electrolyte }\end{array}$ & $2.4 \times 10^{-10} \mathrm{~m}^{2} \mathrm{~s}^{-1}[31]$ \\
\hline$D_{3}$ & $\begin{array}{l}\text { V(III) diffusion coefficient in } \\
\text { electrolyte }\end{array}$ & $2.4 \times 10^{-10} \mathrm{~m}^{2} \mathrm{~s}^{-1}[31]$ \\
\hline$D_{4}$ & $\begin{array}{l}\mathrm{V}(\mathrm{IV}) \text { diffusion coefficient in } \\
\text { electrolyte }\end{array}$ & $3.9 \times 10^{-10} \mathrm{~m}^{2} \mathrm{~s}^{-1}[31]$ \\
\hline$D_{5}$ & $\begin{array}{l}V(V) \text { diffusion coefficient in } \\
\text { electrolyte }\end{array}$ & $3.9 \times 10^{-10} \mathrm{~m}^{2} \mathrm{~s}^{-1}[31]$ \\
\hline$D_{\mathrm{H}_{2} \mathrm{O}}$ & $\begin{array}{l}\text { Water diffusion coefficient in } \\
\text { electrolyte }\end{array}$ & $2.3 \times 10^{-9} \mathrm{~m}^{2} \mathrm{~s}^{-1}[32]$ \\
\hline$D_{w}^{\text {eff }}$ & $\begin{array}{l}\text { Water diffusion coefficient in the } \\
\text { membrane }\end{array}$ & $5.75 \times 10^{-10} \mathrm{~m}^{2} \mathrm{~s}^{-1}[24]$ \\
\hline$D_{\mathrm{H}^{+}}^{\mathrm{eff}}$ & $\begin{array}{l}\text { Proton diffusion coefficient in the } \\
\text { membrane }\end{array}$ & $1.4 \times 10^{-9} \mathrm{~m}^{2} \mathrm{~s}^{-1}[33]$ \\
\hline$D_{\mathrm{HSO}_{4}^{-}}$ & $\begin{array}{l}\mathrm{HSO}_{4}^{-} \text {diffusion coefficient in the } \\
\text { membrane }\end{array}$ & $1.23 \times 10^{-9} \mathrm{~m}^{2} \mathrm{~s}^{-1}[34]$ \\
\hline$D_{\mathrm{SO}_{4}^{2-}}$ & $\begin{array}{l}\mathrm{SO}_{4}^{2-} \text { diffusion coefficient in the } \\
\text { membrane }\end{array}$ & $2.2 \times 10^{-10} \mathrm{~m}^{2} \mathrm{~s}^{-1}[34]$ \\
\hline K & $\begin{array}{l}\text { Kozeny-Carman constant: porous } \\
\text { electrode }\end{array}$ & $5.55[35]$ \\
\hline$k_{\phi}$ & $\begin{array}{l}\text { Electro-kinetic permeability: } \\
\text { membrane }\end{array}$ & $1.13 \times 10^{-19} \mathrm{~m}^{2}[33]$ \\
\hline$k_{p}$ & Hydraulic permeability: membrane & $1.58 \times 10^{-18} \mathrm{~m}^{2}[36]$ \\
\hline$\mu_{\mathrm{H}_{2} \mathrm{O}}$ & Water viscosity & $10^{-3}$ Pa s \\
\hline$\sigma_{s}$ & $\begin{array}{l}\text { Electronic conductivity of porous } \\
\text { electrode }^{\text {a }}\end{array}$ & $500 \mathrm{~S} \mathrm{~m}^{-1}$ \\
\hline$\sigma_{\text {coll }}$ & Electronic conductivity of collectors ${ }^{a}$ & $1000 \mathrm{~S} \mathrm{~m}^{-1}$ \\
\hline
\end{tabular}

a Approximations.

The electrolyte velocity is related to the gradient in liquid pressure according to Eq. (4). The liquid pressure is determined from an overall (liquid) mass balance:

$\nabla \cdot \vec{v}=0$

Combining Eqs. (4) and (7) yields:

$-\frac{d_{f}^{2}}{k \mu} \frac{\epsilon^{3}}{(1-\epsilon)^{2}} \nabla^{2} p=0$

A pseudo-steady state for proton and electron transport is assumed. The electronic potential in the porous carbon electrode is given by Ohm's law:

$-\sigma_{s}^{\mathrm{eff}} \nabla^{2} \psi=-\nabla \cdot \vec{j}$

where $\sigma_{s}^{\text {eff }}$ is the effective conductivity of the porous carbon electrode, obtained from the value for the solid material, $\sigma_{s}$ using the Bruggemann correction: $\sigma_{s}^{\text {eff }}=(1-\epsilon)^{3 / 2} \sigma_{s}$.

For the transport processes in the proton-conducting membrane, the formulation of Bernadi and Verbrugge [20,21] is used. This formulation is known to be more appropriate than the phenomenological model of Springer et al. [24] when the membrane is close to fully saturated. The concentration of water dissolved in the membrane, $c_{\mathrm{H}_{2} \mathrm{O}}$, satisfies the mass balance:

$\frac{\partial c_{\mathrm{H}_{2} \mathrm{O}}}{\partial t}-\nabla \cdot\left(D_{w}^{\text {eff }} \nabla c_{\mathrm{H}_{2} \mathrm{O}}\right)+\nabla \cdot\left(\vec{v} c_{\mathrm{H}_{2} \mathrm{O}}\right)=0$

in which $D_{w}^{\text {eff }}$ is the effective diffusion coefficient for water and $\vec{v}$ is the liquid velocity. The driving forces for the bulk flow are potential and pressure gradients (water molecules form clusters attached to a proton). Schlögl's equation [25] combined with the incompressibility assumption yields:

$\vec{v}=-\nabla \cdot\left(\frac{k_{\phi}}{\mu_{\mathrm{H}_{2} \mathrm{O}}} F c_{\mathrm{H}^{+}} \nabla \phi-\frac{k_{p}}{\mu_{\mathrm{H}_{2} \mathrm{O}}} \nabla p\right)=0$

where $k_{\phi}$ is the electro-kinetic permeability, $k_{p}$ is the hydraulic permeability, $\mu_{\mathrm{H}_{2} \mathrm{O}}$ is the water viscosity, $c_{\mathrm{H}^{+}}$is the proton concentration, and $p$ is the liquid pressure, as before. From the electroneutrality condition the proton concentration satisfies $c_{\mathrm{H}^{+}}=$ $-z_{f} c_{f}$, where $c_{f}$ is the fixed charge site concentration in the membrane and $z_{f}$ is the fixed site charge. The value of $c_{\mathrm{H}^{+}}$is taken as constant. Since protons are the only mobile ions, the equation for current conservation is:

$0=\nabla \cdot \vec{j}=\nabla \cdot \vec{N}_{\mathrm{H}^{+}}=-\sigma_{\mathrm{mem}}^{\mathrm{eff}} \nabla^{2} \phi$

where $\sigma_{\text {mem }}^{\text {eff }}=F^{2} D_{\mathrm{H}^{+}}^{\text {eff }} c_{\mathrm{H}^{+}} /(R T)$ is the effective conductivity of the membrane ( $D_{\mathrm{H}^{+}}^{\text {eff }}$ is the effective diffusion coefficient of the proton).

In the current collectors, Ohm's law can be used to calculate the electronic potential:

$-\sigma_{\text {coll }} \nabla^{2} \psi=0$

where $\sigma_{\text {coll }}$ is the electronic conductivity of the collectors.

The energy balance takes into account heat conduction, convective heat transport and heat generation by reaction and ohmic resistance. As a reasonable first approximation it is assumed that the liquid and solid phases in the electrodes attain the same temperature. This assumption is equivalent to an infinite rate of heat transfer between the two phases and, therefore, instant relaxation to the same temperature. The energy balance is thus:

$\frac{\partial}{\partial t}\left(\overline{\rho C_{p}} T\right)+\nabla \cdot\left(\vec{v} \rho_{l} C_{l} T\right)-\bar{\lambda} \nabla^{2} T=\sum_{k} Q_{k}$

In these equations, $\rho_{l}$ and $C_{l}$ are the density and specific heat capacity of the liquid, respectively, $\bar{\lambda}$ is the volume-averaged thermal conductivity and $\overline{\rho C_{p}}$ is the volume-averaged thermal capacitance:

$\bar{\lambda}= \begin{cases}\epsilon \lambda_{l}+(1-\epsilon) \lambda_{\text {elec }}, & \text { Porous electrode } \\ \lambda_{\text {mem }} & \text { Membrane } \\ \lambda_{\text {coll }} & \text { Current collectors }\end{cases}$

$\overline{\rho C_{p}}= \begin{cases}\epsilon \rho_{l} C_{l}+\rho_{\mathrm{elec}} C_{\mathrm{elec}}(1-\epsilon), & \text { Porous electrode } \\ \rho_{\text {mem }} C_{\text {mem }} & \text { Membrane } \\ \rho_{\text {coll }} C_{\text {coll }} & \text { Current collectors }\end{cases}$

where $C_{j}$ and $\lambda_{j}$ are the specific heat capacities (at constant pressure) and thermal conductivities of the individual phases: the subscripts 'l', 'elec', 'mem' and 'coll' refer to the liquid electrolyte, electrode, membrane and current collector, respectively. The thermal property values used in the simulations are given in Table 4. The values for the electrode are based on Sigratherm ${ }^{\circledR}$ GFA5, the values for the membrane on Nafion ${ }^{\circledR}$ and the values for the current collectors on stainless steel. Values for the electrolyte were based

Table 4

Default parameter values for the heat Eq. (14) and the boundary condition (34).

\begin{tabular}{lll}
\hline Symbol & Quantity & Size \\
\hline$\lambda_{l}$ & Electrolyte thermal conductivity & $0.67 \mathrm{~W} \mathrm{~m}^{-1} \mathrm{~K}^{-1}$ \\
$\lambda_{\text {elec }}$ & Electrode thermal conductivity & $0.15 \mathrm{~W} \mathrm{~m} \mathrm{~K}^{-1}$ \\
$\lambda_{\text {mem }}$ & Membrane thermal conductivity [37] & $0.67 \mathrm{~W} \mathrm{~m}^{-1} \mathrm{~K}^{-1}$ \\
$\lambda_{\text {coll }}$ & Current collector thermal conductivity & $16 \mathrm{~W} \mathrm{~m}^{-1} \mathrm{~K}^{-1}$ \\
$\lambda_{\text {air }}$ & Thermal conductivity of air @ 293 $\mathrm{K}$ & $0.0257 \mathrm{~W} \mathrm{~m}^{-1} \mathrm{~K}^{-1}$ \\
$\rho_{l} C_{l}$ & Liquid thermal capacitance (water) & $4.187 \times 10^{6} \mathrm{~J} \mathrm{~m}^{-3} \mathrm{~K}^{-1}$ \\
$\rho_{\text {elec }} C_{\text {elec }}$ & Porous electrode thermal capacitance a & $3.33 \times 10^{5} \mathrm{~J} \mathrm{~m}^{-3} \mathrm{~K}^{-1}$ \\
$\rho_{\text {mem }} C_{\text {mem }}$ & Membrane thermal capacitance b & $2.18 \times 10^{6} \mathrm{~J} \mathrm{~m}^{-3} \mathrm{~K}^{-1}$ \\
$\rho_{\text {coll }} C_{\text {coll }}$ & Current collector thermal capacitance & $4.03 \times 10^{6} \mathrm{~J} \mathrm{~m}^{-3} \mathrm{~K}^{-1}$ \\
$N u$ & Nusselt number: base case (adiabatic) & 0 \\
$N u$ & Nusselt number: free (forced) convection & $10(50)$ \\
$T_{a}$ & External temperature & $273 \mathrm{~K}$ \\
$-\Delta S_{1}$ & Entropy associated with reaction (1) [38] & $-100 \mathrm{~J} \mathrm{~mol}^{-1} \mathrm{~K}^{-1}$ \\
$-\Delta S_{2}$ & Entropy associated with reaction (2) [38] & $-21.7 \mathrm{~J} \mathrm{~mol}^{-1} \mathrm{~K}^{-1}$ \\
\hline
\end{tabular}

a Estimate based on a specific heat capacity for graphite of $710 \mathrm{~J} \mathrm{~kg} \mathrm{~K}^{-1}$ and a Sigratherm ${ }^{\circledR}$ GFA5 density of $469 \mathrm{~kg} \mathrm{~m}^{-3}$ (68\% porous).

b Estimate based on a specific heat capacity for water and a typical dry density of Nafion $^{\circledR}, 1500 \mathrm{~kg} \mathrm{~m}^{-3}$. 
on water, in the absence of data for the electrolyte. The value of the specific heat capacity of the membrane was also estimated by the value for water (since the bulk of the membrane is liquid water). The thermal conductivity and specific heat capacity of the external environment are approximated by values for air.

In the membrane, the only form of heat transport is conduction. The heat generation terms $Q_{k}$ are defined in Table 5: they represent heating by activation losses, reaction and ohmic resistance. As a simplification, the ohmic heating in the electrolyte solution in the electrodes is based only on the term containing $\sigma_{e}^{\text {eff }}$ in Eq. (5), which would be expected to be the main contributor. This permits a simpler form for the corresponding $Q_{k}$ value.

In Table $5,-\Delta S_{0,1}$ is the standard entropy associated with the reaction in the negative electrode and $-\Delta S_{0,2}$ is the standard entropy associated with the positive electrode reaction. These standard reaction entropies are given by

$\Delta S_{0, j}=\left(\sum_{\text {products }} S_{0, j}^{\text {products }}\right)-\left(\sum_{\text {reactants }} S_{0, j}^{\text {reactants }}\right)$

where $S_{0, j}^{\text {products }}\left(S_{0, j}^{\text {reactants }}\right)$ are the standard entropies of formation of the products (reactants) in reaction $j=1,2$. Their values at $298.15 \mathrm{~K}$ are listed in Table 4 . For each reaction $j$, the standard reaction entropy is related to the standard Gibbs free energy change of the reaction, $\Delta G_{0, j}$, and the standard enthalpy change of reaction, $\Delta H_{0, j}$, by the thermodynamic relation:

$\Delta G_{0, j}=\Delta H_{0, j}+T \Delta S_{0, j}$

Using Eq. (17) and the relation $\Delta G_{0, j}=-n F E_{0, j}$, where $E_{0, j}$ is the standard potential of reaction $j$, the temperature dependence of $\Delta S_{0, j}$ is obtained:

$-n F \frac{\partial \Delta E_{0, j}}{\partial T}=\frac{\partial \Delta G_{0, j}}{\partial T}=\Delta S_{0, j}$

The standard potentials, as functions of temperature, are given in Eq. (22).

\subsection{Reaction kinetics}

The reversible electrochemical reactions taking place on the solid surfaces of the porous carbon electrode are represented by the Butler-Volmer law. Assuming equal transfer coefficients for the forward and backward reactions involving a single electron transfer at both electrodes, the transfer current densities are

$$
\begin{aligned}
& \nabla \cdot \vec{j}_{1}=n \epsilon A F k_{1} \sqrt{c_{3}^{s} c_{2}^{s}}\left\{\exp \left(\frac{F \eta_{1}}{2 R T}\right)-\exp \left(-\frac{F \eta_{1}}{2 R T}\right)\right\} \\
& \nabla \cdot \vec{j}_{2}=n \epsilon A F k_{2} \sqrt{c_{4}^{s} c_{5}^{s}}\left\{\exp \left(\frac{F \eta_{2}}{2 R T}\right)-\exp \left(-\frac{F \eta_{2}}{2 R T}\right)\right\}
\end{aligned}
$$

is the number of electrons transferred; $A$ is the specific (per unit volume of catalyst layer) active surface area of the electrode (solid-liquid interface); $k_{1}$ and $k_{2}$ are the standard rate constants for reactions (1) and (2), respectively; and $\eta_{1}$ and $\eta_{2}$ are the activation overpotentials, in the negative and positive electrode, respectively. The activation overpotentials are defined as follows:

$\eta_{1}=\phi_{s}-\phi_{e}-E_{0,1}^{\prime} ; \quad \eta_{2}=\phi_{s}-\phi_{e}-E_{0,2}^{\prime}$

where $E_{0,1}^{\prime}$ and $E_{0,2}^{\prime}$ are the open-circuit potentials for reactions (1) and (2) respectively, estimated from the relevant Nernst equations:

$E_{0,1}^{\prime}=E_{0,1}-\frac{R T}{F} \ln \left(\frac{c_{2}}{c_{3}}\right)$

$E_{0,2}^{\prime}=E_{0,2}-\frac{R T}{F} \ln \left(\frac{c_{4}}{c_{5}}\right)$

Changes in proton concentration in these expressions are neglected since they are small during typical charge/discharge cycles. The standard potentials $E_{0,1}$ and $E_{0,2}$ are functions of temperature. The measured temperature dependence can be found in [26]:

$$
\begin{gathered}
E_{0,1}=E_{1}^{0}+1.5 \times 10^{-3} \times(T-298.15) \\
E_{0,2}=E_{2}^{0}-9 \times 10^{-4} \times(T-298.15)
\end{gathered}
$$

where $E_{1}^{0}$ and $E_{2}^{0}$ are the standard potentials at $T=298.15 \mathrm{~K}$ for reactions (1) and (2), respectively.

The reaction constants, $k_{1}$ and $k_{2}$ are also temperaturedependent. They can be written in Arrhenius form as follows [27]:

$$
\begin{aligned}
k_{j} & =k_{\text {ref,j }} \exp \left(-\frac{\Delta G_{0, j}}{R}\left[\frac{1}{T_{\text {ref }, \mathrm{j}}}-\frac{1}{T}\right]\right) \\
& =k_{\text {ref,j }} \exp \left(\frac{n F E_{0, j}}{R}\left[\frac{1}{T_{\text {ref }, \mathrm{j}}}-\frac{1}{T}\right]\right)
\end{aligned}
$$

for $j=1,2 . \Delta G_{0, j}=-n F E_{0, j}$ is the standard Gibbs free energy change for the respective reaction and the constant $k_{\text {ref,j }}$ is the values of $k_{i}$ at a reference temperature $T_{\text {ref,j }}$.

The quantities $c_{i}^{s}$ are vanadium-species concentrations at the liquid-solid interfaces in the porous regions, which are generally different from the bulk values due to additional transport resistance (from the bulk solution to the interfaces). They can be related to the bulk values, $c_{i}$, by approximately balancing the rate of reaction with the rate of diffusion of reactant to (or from) the electrode surface at steady state. For this purpose it is convenient to re-write the Butler-Volmer terms in a form that indicates linear dependence on the surface concentrations (found using Eqs. (21) in (19)). For the positive electrode during charge, the balance is

$$
\begin{aligned}
& c_{4}-c_{4}^{s}=\frac{\epsilon k_{1}}{\gamma_{4}}\left\{c_{4}^{s} \exp \left(\frac{F\left(\psi-\phi-E_{0,2}^{\prime}\right)}{2 R T}\right)-c_{5}^{s} \exp \left(-\frac{F\left(\psi-\phi-E_{0,2}^{\prime}\right)}{2 R T}\right)\right\} \\
& c_{5}-c_{5}^{s}=-\frac{\epsilon k_{2}}{\gamma_{5}}\left\{c_{4}^{s} \exp \left(\frac{F\left(\psi-\phi-E_{0,1}^{\prime}\right)}{2 R T}\right)-c_{5}^{s} \exp \left(-\frac{F\left(\psi-\phi-E_{0,1}^{\prime}\right)}{2 R T}\right)\right\}
\end{aligned}
$$

\begin{tabular}{|c|c|c|c|c|}
\hline Term & Membrane & - ve electrode & + ve electrode & Current collector \\
\hline Qact & 0 & $\eta_{1} \nabla \cdot \vec{j}_{1}$ & $\eta_{2} \nabla \cdot \vec{j}_{2}$ & 0 \\
\hline$Q_{\text {rev }}$ & 0 & $-\Delta S_{1} T \nabla \cdot \vec{j}_{1} / F$ & $\Delta S_{2} T \nabla \cdot \vec{j}_{2} / F$ & 0 \\
\hline$Q_{\text {ohm }}$ & $\sigma_{\mathrm{mem}}^{\mathrm{eff}}|\nabla \phi|^{2}$ & $\sigma_{s}^{\text {eff }}|\nabla \psi|^{2}+\sigma_{e}^{\text {eff }}|\nabla \phi|^{2}$ & $\sigma_{s}^{\text {eff }}|\nabla \psi|^{2}+\sigma_{e}^{\text {eff }}|\nabla \phi|^{2}$ & $\sigma_{\text {coll }}|\nabla \psi|^{2}$ \\
\hline
\end{tabular}

for the negative and positive electrode respectively. The various symbols in these expressions are defined as follows: $n=1$ where $\gamma_{4}=D_{4} / d$ and $\gamma_{5}=D_{5} / d$. $d$ is the average pore diameter in the porous carbon electrode and, as before, $D_{i}$ is the diffusion

Table 5

Sources and sinks for the energy equation (14). They are, from top to bottom, heating by activation losses, electrochemical reaction and ohmic resistance. 
Table 6

Default values of the constants related to electrochemistry.

\begin{tabular}{lll}
\hline Symbol & Quantity & Size \\
\hline$k_{1}$ & Standard rate constant: reaction (1) ${ }^{\mathrm{a}}$ & $1.75 \times 10^{-7} \mathrm{~m} \mathrm{~s}^{-1}$ \\
$k_{2}$ & Standard rate constant: reaction (2) & $3 \times 10^{-9} \mathrm{~m} \mathrm{~s}^{-1}[19]$ \\
$E_{0,1}^{\prime}$ & Equilibrium potential: V(II)/V(III) & $-0.255 \mathrm{~V} \mathrm{[39]}$ \\
$E_{0,2}^{\prime}$ & Equilibrium potential: V(IV)/V(V) & $1.004 \mathrm{~V} \mathrm{[39]}$ \\
$c_{f}$ & Fixed charge site (sulfonate) concentration & $1200 \mathrm{~mol} \mathrm{~m}^{-3}[20]$ \\
$z_{f}$ & Charge of fixed (sulfonate) sites & -1 \\
\hline
\end{tabular}

a Fitted parameter.

coefficient for species $i$ in solution. The quantities $\gamma_{i}$, measuring the rate of reactant delivery to or from the surfaces by diffusion from the bulk, are the so-called "piston velocities" (in $\mathrm{m} \mathrm{s}^{-1}$ ). Solving these simultaneous equations for $c_{\mathrm{IV}}^{s}$ and $c_{\mathrm{V}}^{s}$ gives:

$$
\begin{aligned}
c_{4}^{s} & =\frac{c_{4}+\epsilon k_{2} e^{-F\left(\psi-\phi-E_{0,2}^{\prime}\right) /(2 R T)}\left(c_{4} / \gamma_{5}+c_{5} / \gamma_{4}\right)}{1+\epsilon k_{2}\left(e^{-F\left(\psi-\phi-E_{0,2}^{\prime}\right) /(2 R T)} / \gamma_{5}+e^{F\left(\psi-\phi-E_{0,2}^{\prime}\right) /(2 R T)} / \gamma_{4}\right)} \\
c_{5}^{s} & =\frac{c_{5}+\epsilon k_{2} e^{F\left(\psi-\phi-E_{0,2}^{\prime}\right) /(2 R T)}\left(c_{4} / \gamma_{5}+c_{5} / \gamma_{4}\right)}{1+\epsilon k_{2}\left(e^{-F\left(\psi-\phi-E_{0,2}^{\prime}\right) /(2 R T)} / \gamma_{5}+e^{F\left(\psi-\phi-E_{0,2}^{\prime}\right) /(2 R T)} / \gamma_{4}\right)}
\end{aligned}
$$

These expressions are used in the reaction rates (19) to eliminate the surface concentrations in favour of the bulk values. Similar equations apply to the reactant concentrations at the negative electrode. The electrochemical property values used in the simulations are given in Table 6.

\subsection{Initial and boundary conditions}

At the interfaces between the membrane and electrodes, the vanadium species and electron fluxes are considered to be zero in the normal $(x)$ direction (reactants and electrons do not penetrate the membrane). Except at the inlet and outlet surfaces, the normal components of the species fluxes are zero at the external boundaries:

$\vec{N}_{i} \cdot \vec{n}=0 \begin{cases}x=x_{1} \text { and } x=x_{4} & \\ x=x_{2} \text { and } x=x_{3} & i=2,3,4,5 \\ y=0 \text { and } y=h & \text { (Except inlet and outlet surfaces) }\end{cases}$

$-\sigma_{s}^{\mathrm{eff}} \nabla \psi \cdot \vec{n}=0\left\{\begin{array}{l}x=x_{2} \text { and } x=x_{3} \\ y=0 \text { and } y=h\end{array}\right.$

The proton flux at the interfaces between the current collectors and electrodes is zero in the normal $(x)$ direction:

$-\nabla \cdot\left(\kappa^{\mathrm{eff}} \nabla \phi+F \sum_{i} z_{i} \epsilon^{3 / 2} D_{i} \nabla c_{i}\right) \cdot \vec{n}=0 ;$

$x=x_{1} \quad$ and $\quad x=x_{4}$

and protons do not leave the membrane region through the top and bottom boundaries:

$-\frac{F^{2}}{R T} D_{\mathrm{H}^{+}}^{\mathrm{eff}} c_{\mathrm{H}^{+}} \nabla \phi \cdot \vec{n}=0 ; \quad y=0 \quad$ and $\quad y=h \quad$ (Membrane)

Note that the proton flux across the membrane in the $x$ direction is non-zero. At the interfaces between the electrodes and membrane the proton concentration is constrained to satisfy $c_{\mathrm{H}^{+}}=c_{f}$.

The liquid pressure satisfies a Neumann condition at the boundaries, except the inlet and outlet surfaces:

$\nabla p \cdot \vec{n}=0 \quad$ (Except inlet and outlet surfaces)
At the inlets, each species enters with a prescribed bulk velocity and a concentration that depends on the pump rate (see below):

$c_{i}=c_{i}^{\text {in }}(t) ; \quad v_{y}=v_{\text {in }} \quad$ (Inlets)

At the outlets, the liquid pressure is prescribed and all of the reactant diffusive fluxes are set to zero, in the so-called fully-developed flow approximation:

$-\epsilon^{3 / 2} D_{i} \nabla c_{i} \cdot \vec{n}=0 ; \quad p=p_{\text {out }}$ (Outlets)

For the temperature, a combination of boundary conditions is considered for the external surfaces. The default boundary condition is a zero heat flux (corresponding to adiabatic conditions), except at the inlets and outlets:

$-\bar{\lambda} \nabla T \cdot \vec{n}=0$

A non-zero heat flux at the current collector surfaces, $x=0$ and $x=x_{5}$ (corresponding to cooling or heating as a consequence of a fixed external temperature) is investigated in Section 3.4:

$-\bar{\lambda} \nabla T \cdot \vec{n}=\frac{\lambda_{\text {air }} N u}{h}\left(T-T_{a}\right)$

where $T_{a}$ is the (fixed) temperature of the environment, $\lambda_{\text {air }}$ is the thermal conductivity of the surrounding fluid (taken to be air), $h$ is the electrode height and $\mathrm{Nu}$ is the Nusselt number associated with the heat transfer.

The temperature at the inlets is given separately as

$T=T^{\text {in }}$

where $T^{\text {in }}$ is defined below. At the outlets the conductive heat flux is zero.

In the galvanostatic operation of the cell, the current is assumed to enter or leave uniformly through the current collectors, manifested through the following flux conditions (during charge):

$-\sigma_{\text {coll }} \nabla \psi \cdot \vec{n}= \begin{cases}-\frac{I_{\mathrm{app}}}{a} & x=0 \\ \frac{I_{\mathrm{app}}}{a} & x=x_{5}\end{cases}$

where $I_{\mathrm{app}}$ is the current and $a$ is the electrode surface area. For discharge conditions the signs are reversed.

Consistent initial conditions are prescribed for the concentrations and potentials, as follows:

$c_{i}=c_{i}^{0} ; \quad \psi=E_{0,1} ; \quad \phi=0 \quad$ Negative electrode

$c_{i}=c_{i}^{0} ; \quad \psi=E_{0,2} ; \quad \phi=0 \quad$ Positive electrode

The initial temperature is uniform throughout the cell:

$T(t=0)=T_{0}$

In the simulations, the cell voltage (current flowing), $E_{\text {cell }}$, was measured with respect to the potentials at the intersections between the current collectors and electrodes, along $y=h$ in Fig. 1. This is equivalent to an experimental arrangement in which the cell voltage is measured from the potential difference across an opencircuit cell, i.e., with conditions pertaining to the cell outlets.

\subsection{Reservoir and recirculation model}

Invoking conservation of volume the volumetric flow rate at the outlet boundaries, with cross-sectional area $A_{\text {out }}$, is $\omega=v_{\text {in }} \in A_{\text {out }}$. From the calculated average concentration at the relevant outflow boundary, $c_{i}^{\text {out }}$ (found by integrating along the outlet surface), the inlet concentrations are approximated from the following mass balance, which assumes instantaneous mixing and negligible reaction in the reservoir of volume $V$ [17]:

$\frac{d c_{i}^{\text {in }}}{d t}=\frac{\omega}{V}\left(c_{i}^{\text {out }}-c_{i}^{\text {in }}\right) ; \quad c_{i}^{\text {in }}(0)=c_{i}^{0}$ 
where, as defined above, $c_{i}^{0}$ is the initial concentration of species $i$ (water, vanadium species, protons and anions). The total volume of electrolyte on each side of the battery, $V_{T}$, is the sum of the electrode and the reservoir volumes, $\epsilon h L_{t} L_{w}$ and $V$ respectively, where $h$ is the height of the porous carbon electrode, $L_{t}$ its thickness and $L_{w}$ its width (see Table 1 for values). It was assumed that the volume in the pipes is negligible. The inlet temperature is determined by a heat balance performed along similar lines (assuming that the density and specific heat capacity of the solutions are constant and that instantaneous mixing occurs in the reservoirs):

$\frac{d T^{\text {in }}}{d t}=\frac{\omega}{V}\left(T^{\text {out }}-T^{\text {in }}\right) ; \quad T^{\text {in }}(0)=T_{0}$

where $T^{\text {out }}$ is the average temperature at the relevant outflow boundary.

\subsection{Numerical details and parameter values}

The model presented above was solved using the COMSOL Multiphysics ${ }^{\circledR}$ package, with a combination of the convection-diffusion, general-form and ODE options. The package is based on the finite-element method; a quadratic basis was used in all of the simulations, together with a minimum of 2548 elements and a maximum of 7256 elements. The relative error tolerance was set to $1 \times 10^{-6}$.

In order to match the simulated and experimental cell voltage at the beginning of charge in the base case, the entire cell voltage curve was shifted vertically upwards by $131 \mathrm{mV}$. The origin of this lumped fitting parameter is likely to be contact resistance, although mass-transfer resistance in the tubing, stagnant regions in the electrode and leaks could also play a role. For all calculations, the same value of $131 \mathrm{mV}$ was used, since a thorough characterisation of the discrepancy, particularly its dependence on operating conditions, is not yet available.

The standard rate constant $k_{\text {ref, } 1}$ was estimated to be $1.75 \times$ $10^{-7} \mathrm{~m} \mathrm{~s}^{-1}$ by comparing simulated and experimental results at $303 \mathrm{~K}$ [17]. The value of $k_{\mathrm{ref}, 2}$ was estimated from the data in [19] at $293 \mathrm{~K}$.

The default set of operating conditions is given in Table 7. The default parameter values for the simulations are given in Tables 1 , 3,4 and 6 . These values were used unless otherwise stated, and the calculation corresponding to these values is termed the 'base case'.

\section{Results and discussion}

\subsection{Variations in the system temperature}

Fig. 2 shows the evolutions of the cell voltage during a charge/discharge cycle for three initial temperatures, $T_{0}=293 \mathrm{~K}$

Table 7

Default initial and boundary values. The concentration of $\mathrm{SO}_{4}^{2-}$ at all times (including $t=0)$ is determined by the condition of electroneutrality.

\begin{tabular}{lll}
\hline Symbol & Quantity & Value \\
\hline$T_{0}$ & Initial system temperature $^{0}$ & $303 \mathrm{~K}$ \\
$c_{3}^{0}$ & Initial V(III) concentration $^{\mathrm{a}}$ & $1053 \mathrm{~mol} \mathrm{~m}^{-3}$ \\
$c_{2}^{0}$ & Initial V(II) concentration $^{0}$ & $27 \mathrm{~mol} \mathrm{~m}^{-3}$ \\
$c_{4}^{0}$ & Initial V(IV) concentration $^{\mathrm{a}}$ & $1053 \mathrm{~mol} \mathrm{~m}^{-3}$ \\
$c_{5}^{0}$ & Initial V(V) concentration $^{0}$ & $27 \mathrm{~mol} \mathrm{~m}^{-3}$ \\
$c_{d}^{0}$ & Initial water concentration $^{0}$ & $4.2 \times 10^{3} \mathrm{~mol} \mathrm{~m}^{-3}$ \\
$c_{\mathrm{HSO}_{4}^{-}}^{0}$ & Initial HSO $_{4}^{-}$concentration $^{\mathrm{b}}$ & $1200 \mathrm{~mol} \mathrm{~m}^{-3}$ \\
$c_{\mathrm{H}^{+}}^{0}$ & Initial H$^{+}$concentration $^{\mathrm{b}}$ & $1200 \mathrm{~mol} \mathrm{~m}^{-3}$ \\
$p_{\text {out }}$ & Negative electrode outlet pressure $^{0}$ & $300 \mathrm{kPa}^{-1}$ \\
$I_{\mathrm{app}}$ & Volumetric flow rate & $1 \mathrm{~mL} \mathrm{~s}^{-1}$ \\
\hline
\end{tabular}

a This value is based on an initial state of charge of $5 \%$.

b Estimate based on the value of $c_{f}$.

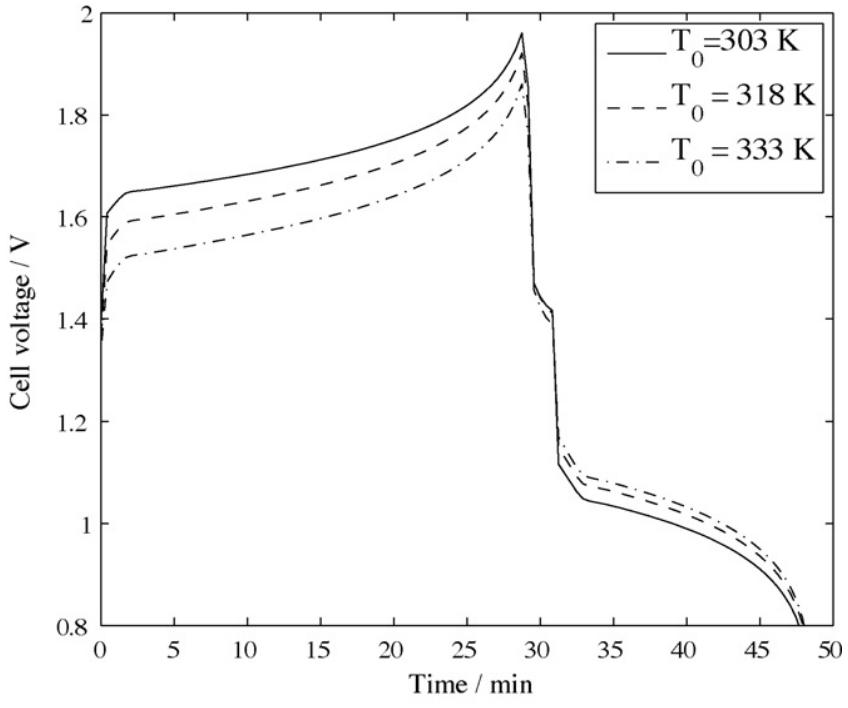

Fig. 2. Simulated charge-discharge curves for three initial temperatures: $T_{0}=$ $303 \mathrm{~K}, 318 \mathrm{~K}$ and $333 \mathrm{~K}$. The times to charge and discharge are approximately $29.2 \mathrm{~min}$ and $45.2 \mathrm{~min}$ in each case, respectively. Two minutes at zero current were simulated before discharge. See Tables 1, 3, 4, 6 and 7 for the other parameter values.

$303 \mathrm{~K}$ and $323 \mathrm{~K}$. The other parameter values are as in Tables 1, 3, 4, 6 and 7. In all three cases the system is assumed to be adiabatic. The scenario in which heat is allowed to escape is discussed below. In each case, charging was terminated at the equivalent state of charge (SOC), which was estimated by the residual V(III) reactant concentration:

$\mathrm{SOC}=1-\frac{c_{3, \mathrm{av}}}{c_{3}^{0}}$

where zero corresponds to no charge and unity to a fully charged. The quantity $c_{3, \text { av }}$ is the average $\mathrm{V}(\mathrm{III})$ concentration in the negative half-cell, including both the electrode and reservoir volumes. It is calculated from a volume average. A value of $\mathrm{SOC}=0.7$ was used in all calculations.

The charge time was within $5 \mathrm{~s}$ of $1752 \mathrm{~s}$ for each of the three temperatures. In each calculation, at the end of the charge period, 2 min of operation at zero current followed by discharge were simulated. During charge, there is a clear decrease in the cell voltage as the temperature is raised and during discharge the cell voltage is increased, i.e., the deviation of the cell voltage from the equilibrium value decreases as the temperature is increased. The capacity of the battery (proportional to time since the discharge current is constant) increases mildly with increased temperature. The decreasing deviation of the cell voltage from the equilibrium value with increasing temperature is due to several factors. Firstly, the equilibrium potentials given by Eqs. (21) and (22) decrease in magnitude for fixed initial concentrations of the reactants. This is evident from the downward trend in the cell voltage value near $t=0$ in Fig. 2 as the temperature is increased.

An increased temperature also increases the rate constants, $k_{i}$ given in Eq. (23). Fig. 3 shows contours of the overpotential in the negative electrode at the end of the charge phase for the two cases $T_{0}=303 \mathrm{~K}$ and $T_{0}=333 \mathrm{~K}$ in Fig. 2 . As the temperature increases, the magnitude of the overpotential decreases, by more than $10 \mathrm{mV}$ at the intersection between the outlet and the membrane, $x=10.3 \mathrm{~mm}, y=10 \mathrm{~cm}$. For lower temperatures, the decreased reaction rate constant leads to an increase in the magnitude of the overpotential, assuming constant concentrations, in order to maintain the (fixed) applied current, as is seen from the Butler-Volmer Eqs. (19). Indeed, Fig. 4 shows that the V(III) con- 
centration values at the end of charge for the two temperatures are very close. The other vanadium species concentrations also change little as the temperature is varied. Along any horizontal line, the depletion of V(III) during charge increases as the current collector surface $(x=6.3 \mathrm{~mm}$ ) is approached - the current enters along this surface. The overpotential drops sharply in order to maintain the current, particularly in the upper half of the electrode as the membrane $(x=10.3 \mathrm{~mm})$ is approached. Near $x=6.3 \mathrm{~mm}, y=10 \mathrm{~cm}$, reaction is severely limited by the low V(III) concentration, so that the drop in overpotential is less steep. Note that the potentialdependent exponential in the Butler-Volmer equations would tend to decrease with an increase in temperature, for a fixed potential, which would tend to require an increase in the magnitude of the overpotential. The increase in the reaction constant, however, dominates this effect, ultimately leading to less negative overpotentials. The decreased magnitude of the overpotential at $333 \mathrm{~K}$ (in both the positive and negative electrodes) will lead to decreased rates of side reactions such as oxygen evolution (in the positive electrode) and hydrogen evolution (in the negative electrode) towards the end of charge. This suggests that in order to avoid gas evolution, the target SOC should be reduced if the temperature of the system is decreased.
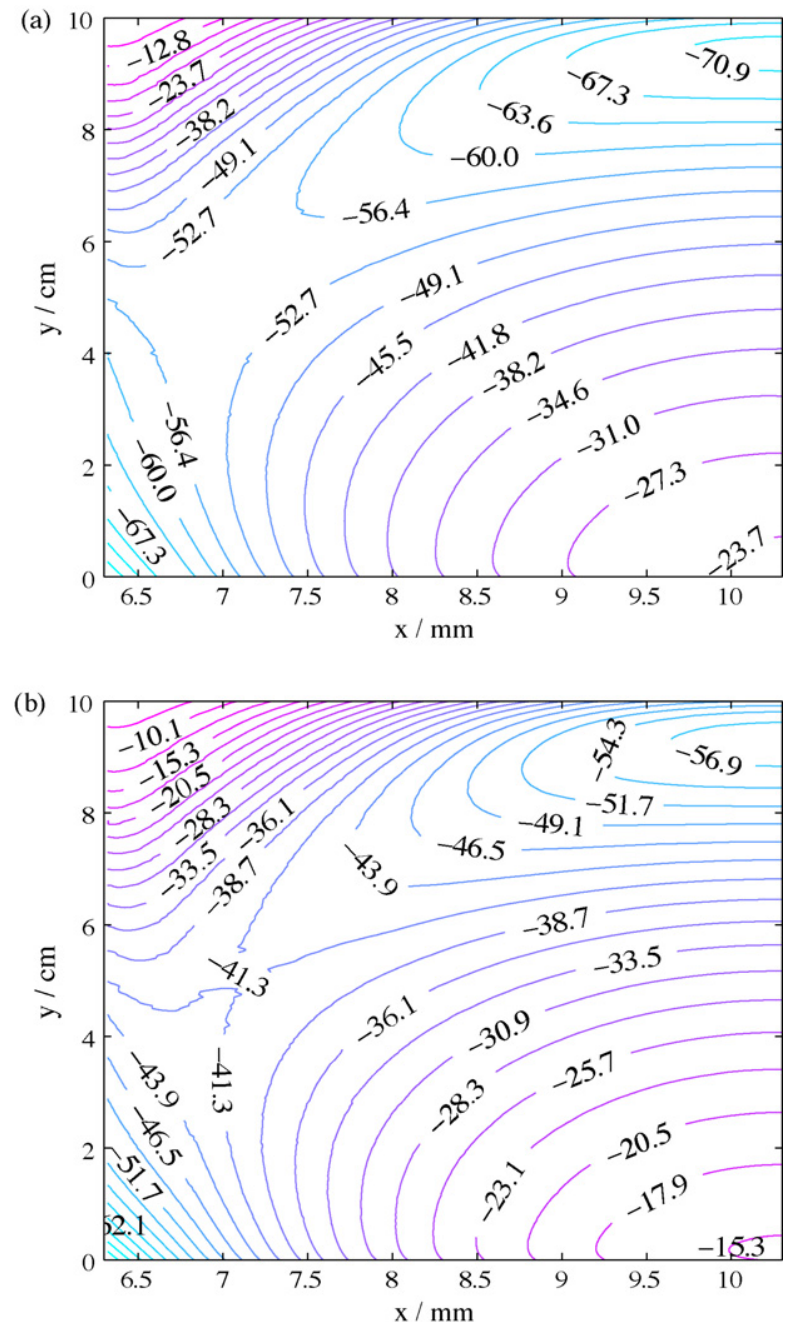

Fig. 3. Contours of overpotential in the negative electrode, $\eta_{1}$ (in $\mathrm{mV}$ ) towards the end of the charge phase, $t=28.75 \mathrm{~min}$, for two the cases $T_{0}=303 \mathrm{~K}$ and $T_{0}=333 \mathrm{~K}$ in Fig. 2. See Tables 1, 3, 4, 6 and 7 for the other parameter values. The left-hand boundary $(x=6.3 \mathrm{~mm}$ ) corresponds to the intersection of the electrode with the current collector and the right-hand boundary $(x=10.3 \mathrm{~mm})$ to the intersection of the electrode with the membrane.
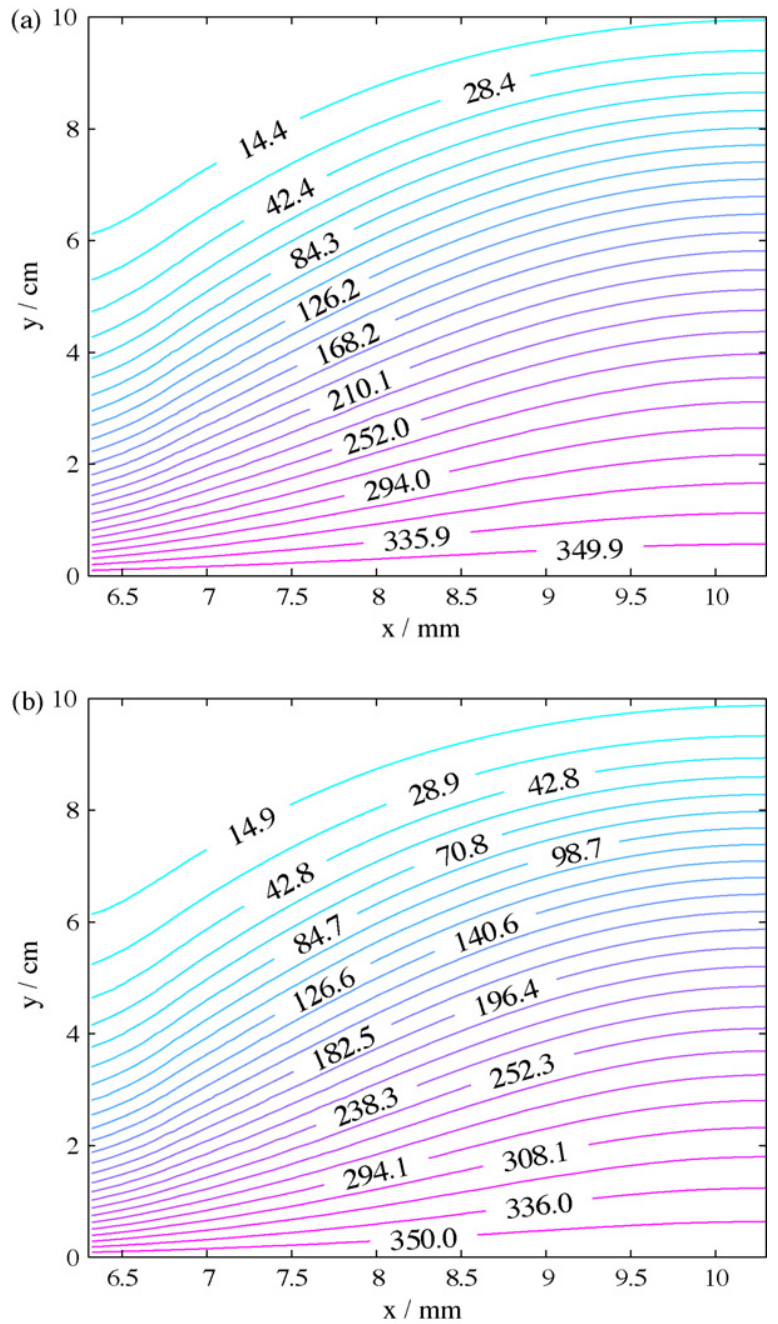

Fig. 4. Contours of $\mathrm{V}(\mathrm{III})$ concentration in the negative electrode (in mol $\mathrm{m}^{-3}$ ) towards the end of the charge phase, $t=28.75 \mathrm{~min}$ for the two cases $T_{0}=303 \mathrm{~K}$ and $T_{0}=333 \mathrm{~K}$ in Fig. 2. See Tables 1, 3, 4, 6 and 7 for the other parameter values. The left-hand boundary $(x=6.3 \mathrm{~mm}$ ) corresponds to the intersection of the electrode with the current collector and the right-hand boundary $(x=10.3 \mathrm{~mm})$ to the intersection of the electrode with the membrane.

Contour plots of the temperature in the cell at the end of the charge and discharge cycles for the case $T_{0}=303 \mathrm{~K}$ are given in Fig. 5. Contours at the other temperatures are qualitatively the same, with roughly equal temperature rises in each case. The various regions are as follows (in mm): current collector $(0 \leq x<6.3)$; negative electrode $(6.3 \leq x<10.3)$; membrane $(10.3 \leq x<10.5)$; positive electrode $(10.5 \leq x<14.5)$; and current collector $(14.5 \leq$ $x \leq 20.8)$. At the end of the charge phase, the cell temperature is almost $2 \mathrm{~K}$ higher than the initial temperature and by the end of the discharge phase, the temperature rise is approximately $3 \mathrm{~K}$ throughout. This represents a significant level of heating (due primarily to the ohmic resistances in Eq. (14)) in a relatively short period of time. These results demonstrate that over the course of several hours, the heat, if not allowed to dissipate, would rise to unacceptable levels.

\subsection{Variations in the applied current}

Fig. 6 shows simulated charge-discharge curves for three applied currents: $I_{\text {app }}=5 \mathrm{~A}, 10 \mathrm{~A}$ and $20 \mathrm{~A}$. The sign of the current is reversed during discharge. In all cases the initial temperature is $T_{0}=303 \mathrm{~K}$. The other parameter values are as in Tables $1,3,4$, 

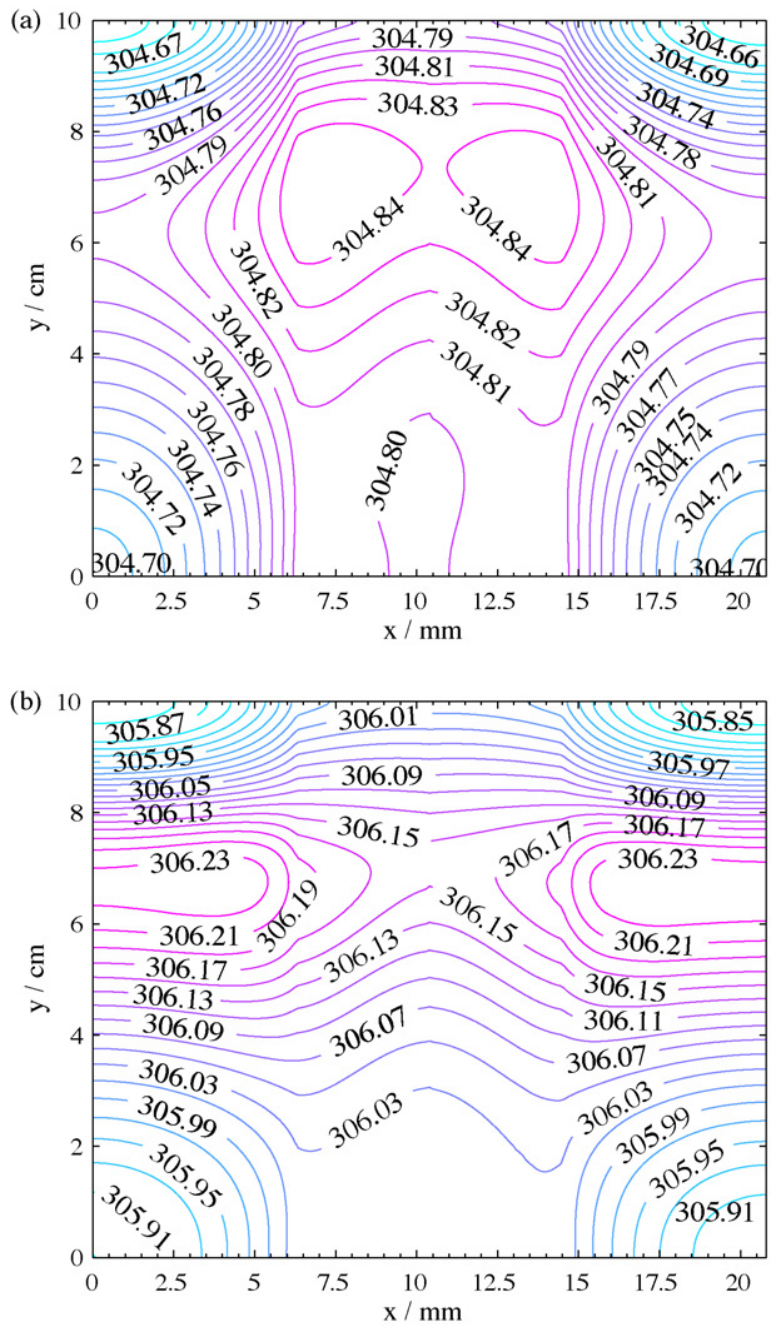

Fig. 5. Contours of the temperature (in K) in the entire cell: (a) towards the end of charge $t=28.75 \mathrm{~min}$ and (b) towards the end of discharge $t=45 \mathrm{~min}$. These plots correspond to the curve at $T_{0}=303 \mathrm{~K}$ in Fig. 2. See Tables 1, 3, 4, 6 and 7 for the other parameter values. The various regions are as follows: current collector $(0 \leq$ $x<6.3$ ), negative electrode $(6.3 \leq x<10.3)$, membrane $(10.3 \leq x<10.5)$, positive electrode $(10.5 \leq x<14.5)$ and current collector $(14.5 \leq x \leq 20.8)$.

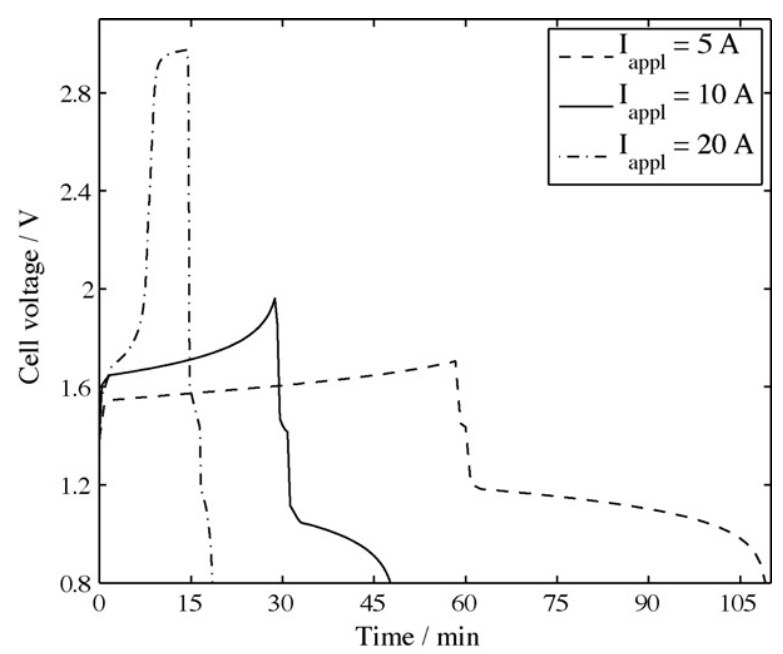

Fig. 6. Simulated charge-discharge curves for three applied currents (the sign of the current is reversed during discharge): $I_{\mathrm{app}}=5 \mathrm{~A}, 10 \mathrm{~A}$ and $20 \mathrm{~A}$. The charge times are defined by an equivalent state of charge for each applied current value. See Tables 1 , $3,4,6$ and 7 for a list of parameter values.
6 and 7. The charge times are defined by an equivalent SOC for each applied current value (the same SOC value used in the calculations in Fig. 2). There is clearly a dramatic increase in the maximum cell voltage as the applied current is increased. At $I_{\mathrm{app}}=20 \mathrm{~A}$, the magnitudes of the overpotentials in the both electrodes rise well above the values required for the onset of hydrogen and oxygen evolution, well before the final SOC is reached. The coulombic efficiency is substantially increased as the magnitude of the applied is current reduced; fixing the end of discharge as the point at which the cell voltage reaches a value of $0.8 \mathrm{~V}$, the coulombic efficiency for $I_{\mathrm{app}}=10 \mathrm{~A}$ is $57 \%$ and for $I_{\mathrm{app}}=5 \mathrm{~A}$, it is $81 \%$. At low loads and over several cycles, self-discharge engendered by reactant crossover may lower the coulombic efficiency, though this is not incorporated into the model.

Fig. 7 shows contours of the overpotential and V(III) concentration in the negative electrode at the end of the charge phase for the case $I_{\text {app }}=5$ A. Comparing the V(III) concentration in Fig. 7(a) with the contour plots in Fig. 4 for $I_{\mathrm{app}}=10$ and $T_{0}=303 \mathrm{~K}$ reveals that the concentration is more uniform (less stratified in the $y$ direction) at the lower value of $I_{\mathrm{app}}$. In particular, $\mathrm{V}(\mathrm{III})$ is not entirely depleted locally at $x=6.3 \mathrm{~mm}, y=10 \mathrm{~cm}$, as was the case for $I_{\mathrm{app}}=10 \mathrm{~A}$. As a consequence, the overpotential is more evenly distributed, which
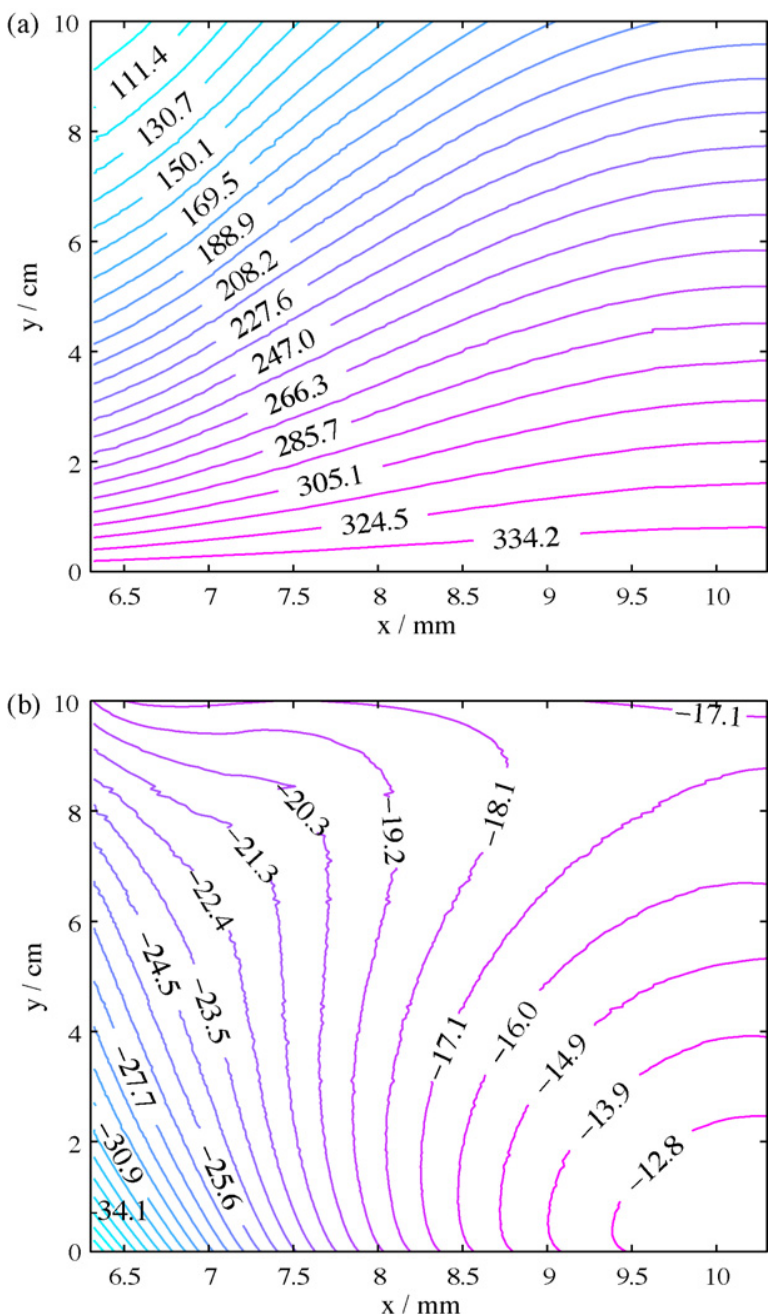

Fig. 7. Contours of overpotential and V(III) concentration in the negative electrode towards the end of the charge phase, $t=58.33 \mathrm{~min}$, for the case $I_{\mathrm{app}}=5 \mathrm{~A}$ in Fig. 6 . See Tables 1, 3, 4, 6 and 7 for the other parameter values. The left-hand boundary ( $x=$ $6.3 \mathrm{~mm}$ ) corresponds to the intersection of the electrode with the current collector and the right-hand boundary $(x=10.3 \mathrm{~mm})$ to the intersection of the electrode with the membrane. 
is seen by comparing Figs. 7(b) and 3(a). Moreover, the magnitudes of the overpotentials are markedly lower for $I_{\mathrm{app}}=5 \mathrm{~A}$, primarily as a result of the lower rates of reaction required to maintain a lower current.

Fig. 8 shows contours of the temperature towards the end of discharge for the two cases $I_{\mathrm{app}}=5 \mathrm{~A}$ and $20 \mathrm{~A}$ depicted in Fig. 6 . While the increase in temperature for the lower value of $I_{\mathrm{app}}$ is approximately $2 \mathrm{~K}$, the increase for $I_{\mathrm{app}}=20 \mathrm{~A}$ is as high as $12 \mathrm{~K}$. This is despite a much shorter timescale; 20 min compared with $100 \mathrm{~min}$. Local maxima in the temperature develop in both current collectors at a height of approximately $3 \mathrm{~cm}$. The distribution of temperature is determined largely by the gradients in electronic and ionic potential, since the majority of heating arises from ohmic resistance (see the form in Table 5). Fig. 9, showing contours of the heat source $Q_{\mathrm{ohm}}$ (in $\mathrm{kW} \mathrm{m}^{-3}$ ) for (a) the current collector adjacent to the negative electrode and (b) the negative electrode at $t=20.83 \mathrm{~min}$ for the case $I_{\mathrm{app}}=20$, demonstrates the influence of the potential gradients on the temperature distribution (the contours in the current collector adjacent to the positive electrode have a similar - laterally inverted - shape). A local maximum in $Q_{\mathrm{ohm}}$ develops in the negative electrode in the vicinity of the inlet, $x=6.3 \mathrm{~mm}, y=0 \mathrm{~cm}$, which outweighs the
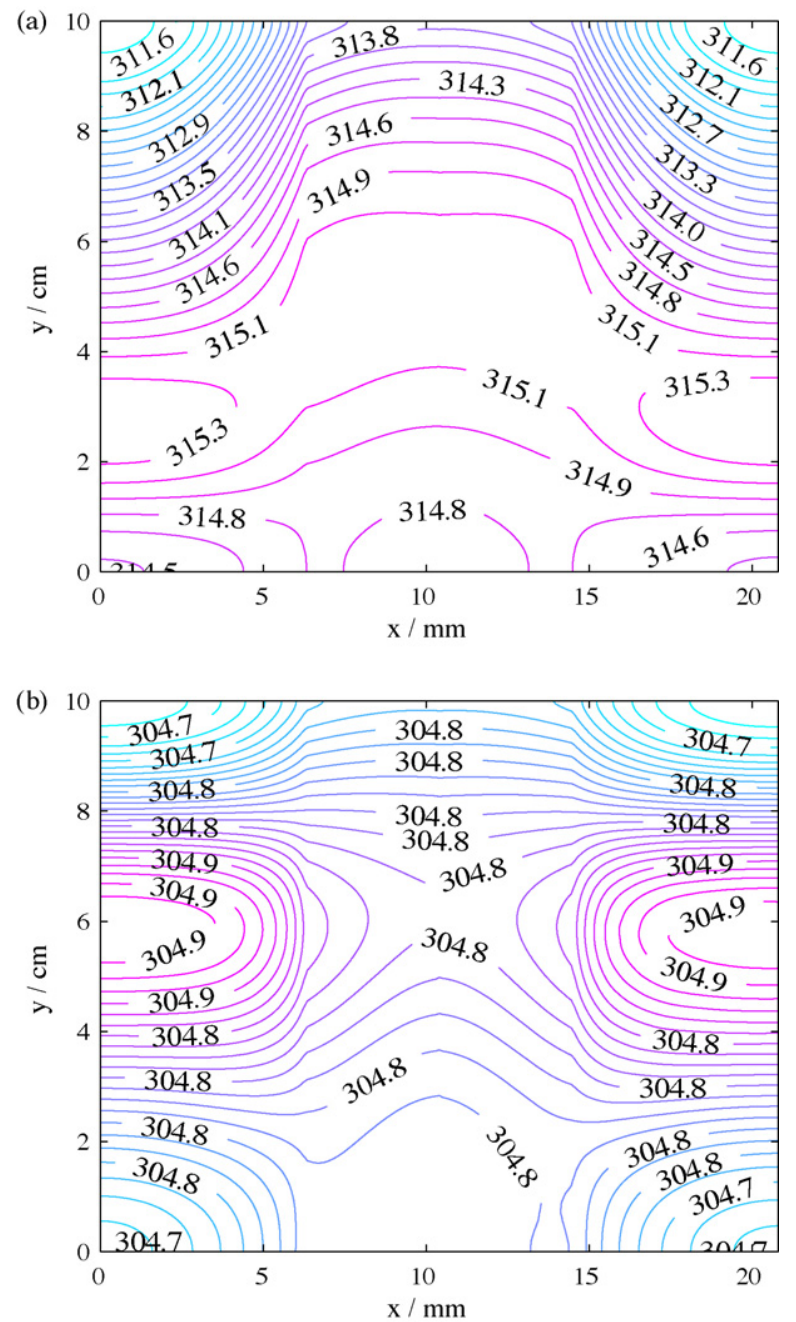

Fig. 8. Contours of the temperature (in the entire cell) towards the end of discharge for the case (a) $I_{\text {app }}=20 \mathrm{~A}, t=18.75 \mathrm{~min}$; and (b) $I_{\mathrm{app}}=5 \mathrm{~A}, t=109.17 \mathrm{~min}$ in Fig. 6 . See Tables 1, 3, 4, 6 and 7 for the other parameter values. The various regions are as follows: current collector $(0 \leq x<6.3)$, negative electrode $(6.3 \leq x<10.3)$, membrane $(10.3 \leq x<10.5)$, positive electrode $(10.5 \leq x<14.5)$ and current collector $(14.5 \leq x \leq 20.8)$.
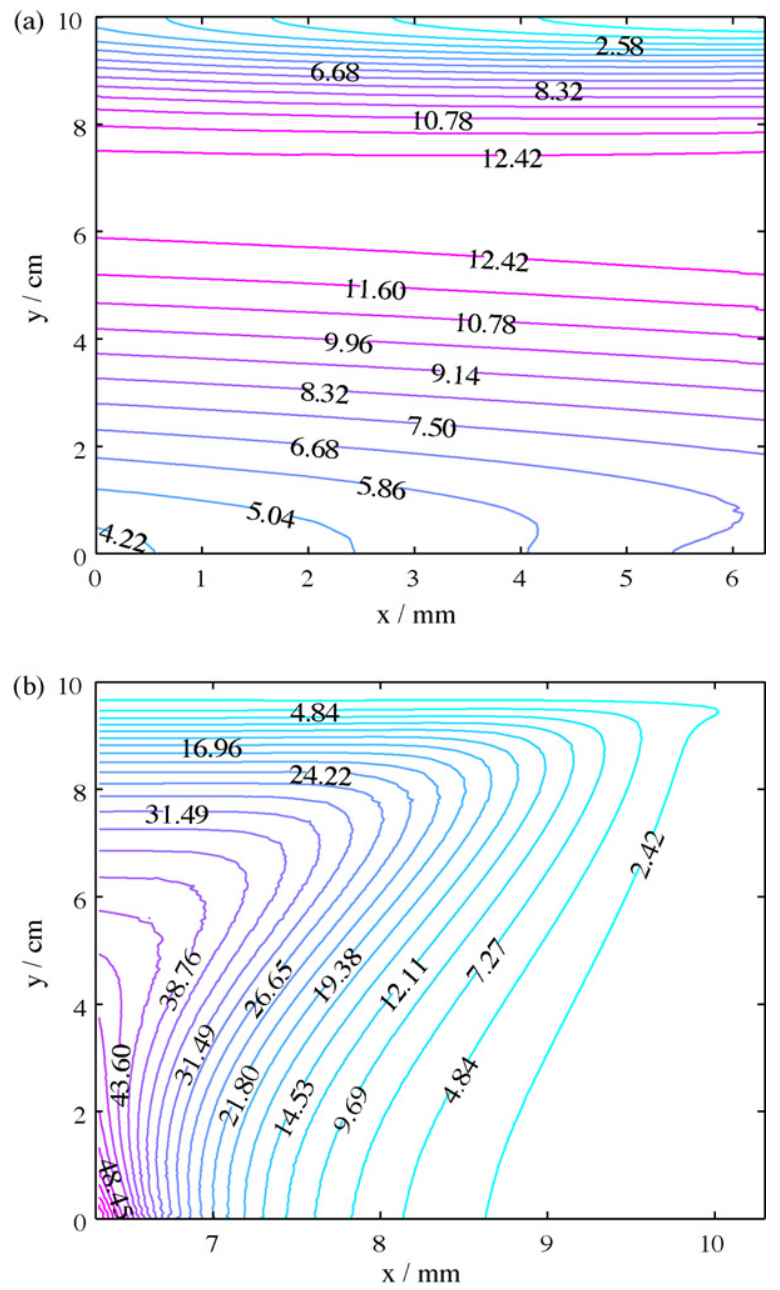

Fig. 9. Contours of the heat source $Q_{\mathrm{ohm}}\left(\right.$ in $\mathrm{kW} \mathrm{m}^{-3}$ ) at the end of the discharge phase, $t=18.75 \mathrm{~min}$, in (a) the current collector adjacent to the negative electrode and (b) the negative electrode. These plots correspond to the case $I_{\text {app }}=20$ A in Fig. 6 . See Tables $1,3,4,6$ and 7 for the other parameter values. $x=0 \mathrm{~mm}$ defines the intersection between the current collector and external environment and $x=10.3 \mathrm{~mm}$ defines the intersection between the electrode ad the ion-exchange membrane.

local maximum in the current collector, at $y \approx 5 \mathrm{~cm}$. This local maximum in the electrode is determined primarily by the gradient of the electronic potential in the $x$ direction, $\partial \phi_{s} / \partial x$; at the higher current density, the greater non-uniformity in the $V($ II) reactant concentration on discharge leads to larger potential gradients in the electrode, which exert a stronger influence over the temperature profile.

\subsection{Variations in the electrolyte flow rate}

The flow (pump) rate of the electrolyte is an important control mechanism in the operation of a vanadium redox flow battery system. At low flow rates the electrolyte is not efficiently circulated and stagnant regions can form in the electrode. If the flow rate is too high, there is a risk of leakage, or the performance gains may not be sufficient to outweigh the extra power required to pump the electrolyte through the system at a faster rate. Fig. 10 compares the charge/discharge curve for the base case with $\omega=0.25 \mathrm{~mL} \mathrm{~s}^{-1}$ with that for $\omega=0.5 \mathrm{~mL} \mathrm{~s}^{-1}$, with all other parameters as in Tables 1,3 , 4, 6 and 7. As the flow rate is increased the coulombic efficiency markedly improves. A higher flow rate reduces the contact time for reaction in the electrode, which leads to a longer time for the exit solution to reach the desired state of charge [17]. The V(III) concen- 


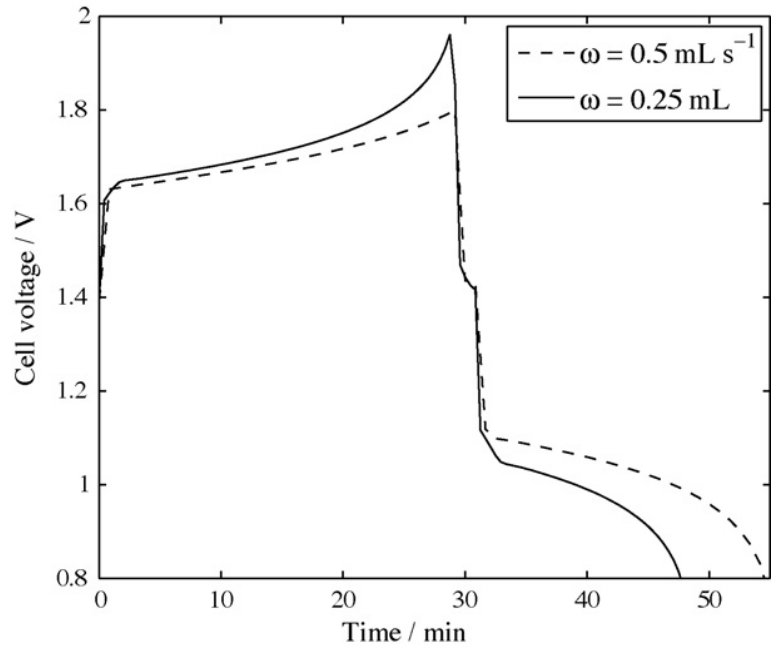

Fig. 10. Simulated charge-discharge curves for two flow rates: $\omega=0.5 \mathrm{~mL} \mathrm{~s}^{-1}$ and the base case of $\omega=0.25 \mathrm{~mL} \mathrm{~s}^{-1}$. See Tables $1,3,4,6$ and 7 for the other parameter values.

tration is more uniform (the reactant in the electrode is replenished from the reservoir more rapidly) leading to greater uniformity in the overpotential and transfer current density. As a result, the cell voltage at the end of charge is lower for $\omega=0.5 \mathrm{~mL} \mathrm{~s}^{-1}$ and the rates of gas-evolution reactions reduced.

Fig. 11 shows the temperature distribution near the end of discharge for $\omega=0.5 \mathrm{~mL} \mathrm{~s}^{-1}$, corresponding to the calculation in Fig. 10. Comparing Fig. 11 with Fig. 5, the difference in the temperature rise between the two flow rates is small. However, the distribution of the temperature is more uniform at the higher flow rate, which is clearly a result of the increased convective transport of heat form the electrodes to the reservoirs, in the absence of changes in other parameters. Furthermore, the localised maxima in temperature seen in Fig. 5 are not as pronounced. Over long timescales, this suggests that the likelihood of localised heating is higher at low flow rates where concentrations, reactions, and, importantly, potentials can be highly stratified.

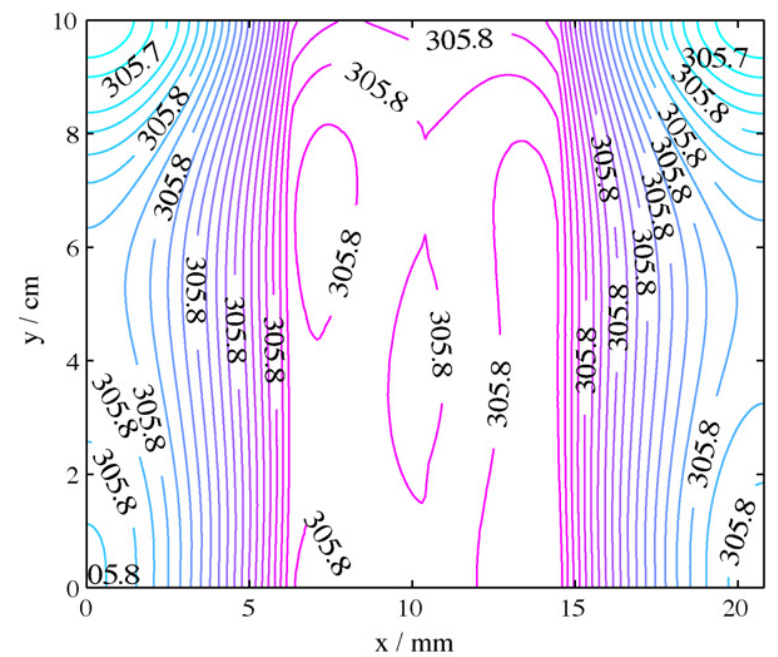

Fig. 11. The temperature distribution in the entire cell near the end of discharge for a flow rate of $\omega=0.5 \mathrm{~mL} \mathrm{~s}^{-1}$, corresponding to the calculation shown in Fig. 10. See Tables 1, 3, 4, 6 and 7 for a list of parameter values. The various regions are as follows: current collector $(0 \leq x<6.3)$, negative electrode $(6.3 \leq x<10.3)$, membrane $(10.3 \leq x<10.5)$, positive electrode $(10.5 \leq x<14.5)$ and current collector $(14.5 \leq x \leq 20.8)$.

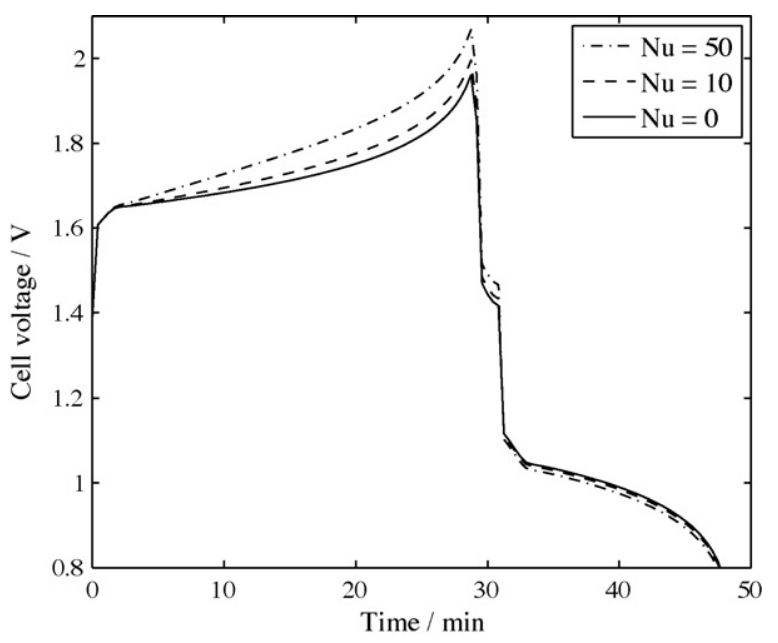

Fig. 12. The effect of a finite rate of heat loss to the external environment. The three cases $N u=0, N u=10$ and $N u=50$ represent adiabatic conditions, free convection and forced convection, respectively. See Tables 1, 3, 4, 6 and 7 for a list of parameter values.
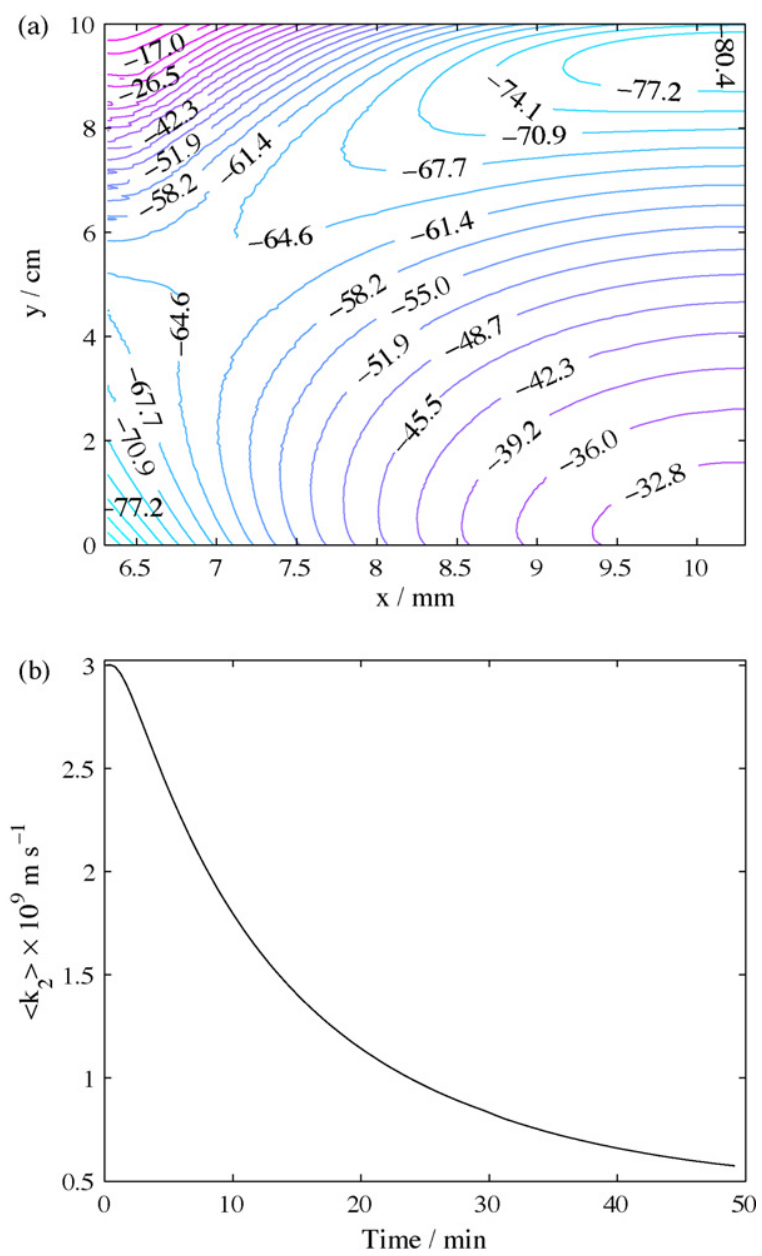

Fig. 13. (a) Contours of overpotential in the negative electrode towards the end of the charge phase, $t=28.75 \mathrm{~min}$, for the case $N u=50$ in Fig. 12 . See Tables $1,3,4,6$ and 7 for the other parameter values. The left-hand boundary $(x=6.3 \mathrm{~mm})$ corresponds to the intersection of the electrode with the current collector and the right-hand boundary $(x=10.3 \mathrm{~mm})$ to the intersection of the electrode with the membrane. (b) The evolution of the spatially averaged value of the rate constant, $k_{2}$ for the positive electrode reaction in the case $\mathrm{Nu}=50$. 


\subsection{Effects of heat loss to the environment}

Thus far it has been assumed that the system is adiabatic. It has been demonstrated above that if heat is not allowed to escape from the system, the temperature can rise to unacceptable levels over relatively short periods of time, particularly for high loads. Fig. 12 demonstrates the effect of a finite rate of heat loss to the external environment. The adiabatic case corresponds to $T_{0}=303 \mathrm{~K}$ with all other parameters as in Tables 1, 3, 4, 6 and 7. The other two curve corresponds to heat loss by natural convection with a Nusselt number of 10 and forced convection with $\mathrm{Nu}=50$. A value of $N u=0$ corresponds to the adiabatic condition and a value of $N u=\infty$ to a fixed temperature $T=T_{a}$ at the boundary. Without loss of generality, the heat loss was applied only to the outermost surfaces of the current collectors in the $x$ direction, $x=0 \mathrm{~mm}$ and $x=20.8 \mathrm{~mm}$.

For the non-adiabatic cases, heat loss lowers the temperature in the electrodes, which leads to a gradual increase in the cell voltage during charge and a lower cell voltage during discharge; during charge, the standard potentials increase with a decreasing temperature and the slower reaction rates at lower temperatures require a
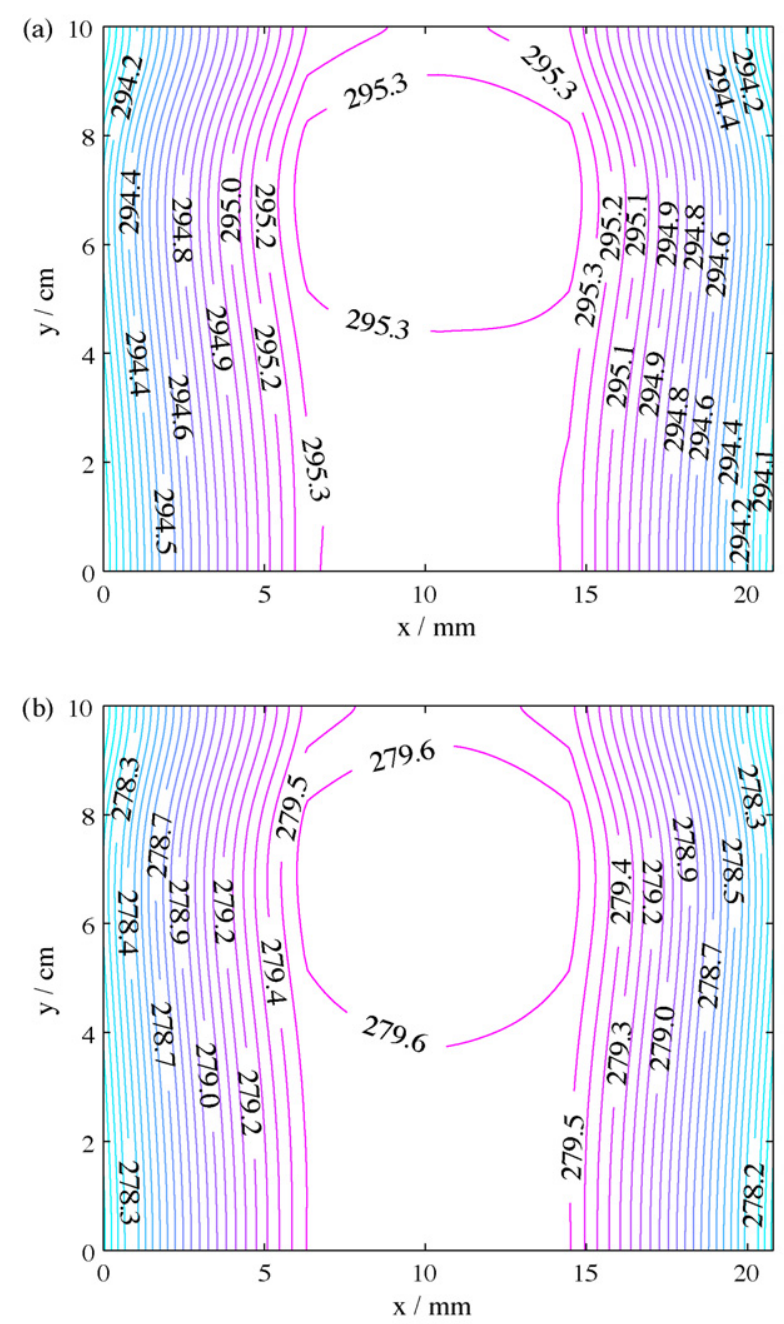

Fig. 14. The distribution of temperature in the entire cell towards the end of discharge, $t=49.17 \mathrm{~min}$, for the two cases (a) $N u=10$ (free convection) and (b) $N u=50$ (forced convection) in Fig. 12. The various regions are as follows: current collector $(0 \leq x<6.3)$, negative electrode $(6.3 \leq x<10.3)$, membrane $(10.3 \leq x<10.5)$, positive electrode $(10.5 \leq x<14.5)$ and current collector $(14.5 \leq x \leq 20.8)$. In both cases the external temperature, along the surfaces $x=0 \mathrm{~mm}$ and $x=20.8 \mathrm{~mm}$, is $T_{a}=273 \mathrm{~K}$. See Tables $1,3,4,6$ and 7 for a list of parameter values. compensating increase in the activation overpotentials. The more heat is lost (Nusselt number is increased) the greater the deviation of the cell voltage from the equilibrium value. Fig. 13(a) shows contours of the overpotential in the negative electrode towards the end of the charge phase, $t=28.75 \mathrm{~min}$, for the case $\mathrm{Nu}=50$. A comparison with Fig. 3(a) shows the greater polarisation with heat loss included. The evolution of the average value of the rate constant in the positive electrode, $\left\langle k_{2}\right\rangle$ is shown in Fig. 13(b). By the end of discharge, the value has decreased by almost an order of magnitude. The decrease in $\left\langle k_{1}\right\rangle$ (not shown) is less pronounced due to the smaller activation energy (Gibbs free energy change), but is still substantial.

Fig. 14 shows the distribution of temperature in the entire cell towards the end of discharge, $t=49.17 \mathrm{~min}$, for the two cases (a) $N u=10$ and (b) $N u=50$. In both cases, the fall in temperature is greatest at the boundaries where heat is lost $(x=0 \mathrm{~mm}$ and $x=20.8 \mathrm{~mm}$ ). While the gradients in temperature in the $x$ direction are relatively large, there is an almost uniform distribution of temperature along any vertical line.

\section{Conclusions}

In this paper, thermal effects have been incorporated in a transient two-dimensional modelling framework for the all-vanadium redox flow battery. The fundamental laws of charge, energy, mass and momentum conservation are solved together with a model for the charge transfer kinetics. One of the benefits of modelling is the ability to predict quantities that can be difficult, in some cases impossible to obtain through in situ experimental measurements. This information, however, can be of vital importance to ensure both good performance and longevity of the battery-knowledge of the likelihood of localised reactant depletion, localised heating and of a steep rise in potential.

High temperatures (caused primarily by large potential gradients) are harmful to perfluorinated membranes, such a Nafion ${ }^{\circledR}$ [28-30], can enhance corrosion of the plates and can lead to water loss. The numerical simulations conducted in this work suggest that without heat dissipation from the cell, the temperature would rise to unacceptable levels in a relatively short period of time. In order to avoid large temperature increases an effective cooling strategy is required for operation in high-temperature environments and under high loads.

Due to non-uniformities in the reactant concentrations and, therefore, potentials and transfer current densities, local maxima in temperature can develop. A large electrolyte flow rate, combined with regulation of the external temperature, could be used to avoid such hotspots by keeping the temperature distribution uniform. Moreover, such high flow rates increase the coulombic efficiency of the cell and lower the rates of hydrogen and oxygen evolution.

The value of the applied current for charge and discharge plays a crucial role in heat generation. The amount of heat generated and the timescale of the temperature rise do not increase linearly with the current. Regions of high temperature can form rapidly in the current collectors and electrodes due to large gradients in the electronic potential.

Heat loss can have a significant effect on the charge/discharge behaviour and temperature distribution of the cell. In the examples presented, cell performance was shown to deteriorate markedly, with increases in the magnitudes of the overpotentials in both electrodes and, therefore, an increased likelihood of gas evolution. These results further highlight the need for an effective heat management strategy to maintain the desired cell temperature, particularly in environments where the temperature is not optimal. 


\section{Acknowledgements}

Parts of this paper were presented by Professor F.C. Walsh at the Annual ISE Meeting at Seville. The work has benefitted from TSB funding on the present and related topics.

\section{Appendix A. Nomenclature}

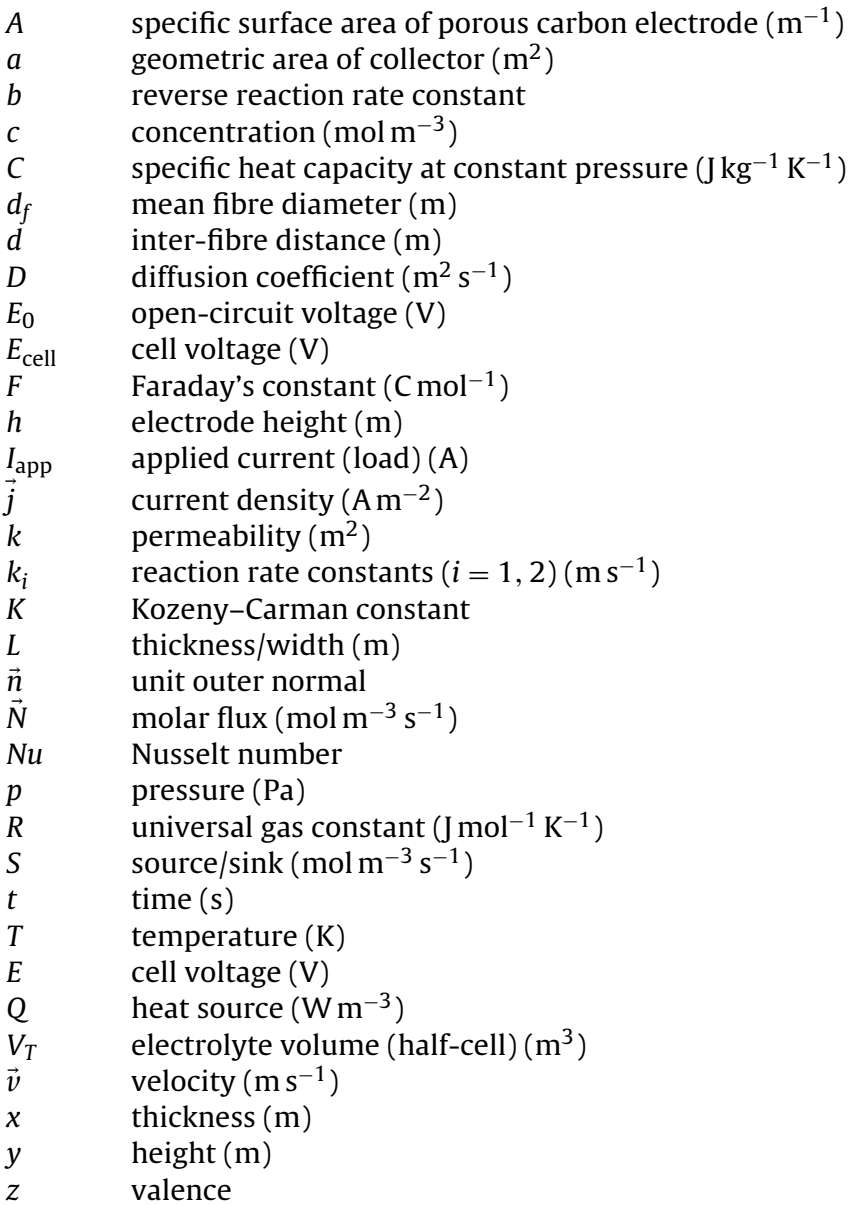

\section{Greek symbols \\ $\gamma \quad$ piston velocity $\left(\mathrm{m} \mathrm{s}^{-1}\right)$ \\ $\epsilon \quad$ volume fraction \\ $\eta \quad$ overpotential (V) \\ $\kappa \quad$ ionic conductivity $\left(\mathrm{S} \mathrm{m}^{-1}\right)$ \\ $\lambda \quad$ thermal conductivity $\left(\mathrm{W} \mathrm{m}^{-1} \mathrm{~K}^{-1}\right)$ \\ $\mu \quad$ dynamic viscosity $\left(\mathrm{kg} \mathrm{m}^{-1} \mathrm{~s}^{-1}\right)$ \\ $\rho \quad$ density $\left(\mathrm{kg} \mathrm{m}^{-3}\right)$ \\ $\sigma \quad$ electronic conductivity $\left(\mathrm{S} \mathrm{m}^{-1}\right)$ \\ $\phi \quad$ protonic potential $(\mathrm{V})$ \\ $\psi \quad$ electronic potential $(\mathrm{V})$ \\ $\omega \quad$ volumetric flow rate $\left(\mathrm{m}^{3} \mathrm{~s}^{-1}\right)$}

$\begin{array}{ll}\text { Subscript } & \\ a & \text { positive electrode quantity } \\ \text { air } & \text { property of air } \\ \text { app } & \text { applied quantity } \\ \text { av } & \text { average value } \\ c & \text { negative electrode quantity } \\ \text { coll } & \text { current collector quantity }\end{array}$

e electrolyte quantity

$f \quad$ fixed charge quantity

$i \quad$ species $i$

in inlet value

$k \quad$ reaction (1) or (2)

$s \quad$ solid or electronic property

$\mathrm{H}_{2} \mathrm{O}$ water property

$w \quad$ water property (membrane)

0 initial or equilibrium value

- $\quad$ negative electrode quantity/property

$+\quad$ positive electrode quantity/property

\section{Superscript \\ eff effective value \\ in inlet value \\ out outlet value \\ $0 \quad$ initial value \\ - $\quad$ volume average}

\section{References}

[1] M. Skyllas-Kazacos, C. Menictas, Proceedings, Intelec, Melbourne, 1997.

[2] The VRB energy storage system: the multiple benefits of integrating the VRBESS with wind energy, Case studies in MWH applications, Technical report, VRB Power Systems Inc, www.vrbpower.com/docs/whitepapers/, 2007.

[3] C. Ponce de Léon, A. Frías-Ferrer, J. González-Garcia, D.A. Szánto, F.C. Walsh, J. Power Sources 160 (2006) 716.

[4] M. Skyllas-Kazacos, R.G. Robins, US Patent 849 094, 1986.

[5] E. Sum, M. Skyllas-Kazacos, J. Power Sources 15 (1985) 179.

[6] M. Skyllas-Kazacos, F. Grossmith, J. Electrochem. Soc. 134 (1987) 2950.

[7] J. Newman, W. Tiedemann, J. Electrochem. Soc. 144 (1997) 3081.

[8] C.Y. Wang, W.B. Gu, B.Y. Liaw, J. Electrochem. Soc. 145 (1998) 3407.

[9] C.Y. Wang, W.B. Gu, B.Y. Liaw, J. Electrochem. Soc. 145 (1998) 3418.

[10] M. Doyle, T.F. Fuller, J. Newman, J. Electrochem. Soc. 140 (1993) 1526

[11] T.F. Fuller, M. Doyle, J. Newman, J. Electrochem. Soc. 141 (1994) 1.

[12] T.I. Evans, T.V. Nguyen, R.E. White, J. Electrochem. Soc. 136 (1989) 328

[13] A.A. Shah, G.S. Kim, W. Gervais, A. Young, K. Promislow, J. Li, S. Yi, J. Power Sources 160 (2006) 1251

[14] A.A. Shah, G.S. Kim, P.C. Sui, D. Harvey, J. Power Sources 163 (2007) 793.

[15] A.A. Shah, P.C. Sui, G.S. Kim, S. Ye, J. Power Sources 166 (2007) 1.

[16] A.A. Shah, F.C. Walsh, J. Power Sources 185 (2008) 287.

[17] A.A. Shah, M.J. Watt-Smith, F.C. Walsh, Electrochim. Acta 53 (2008) 8087

[18] Ch. Fabjan, J. Garche, B. Harrer, L. Jörissen, C. Kolbeck, F. Philippi, G. Tomazic, F. Wagner, Electrochim. Acta 47 (2001) 825

[19] M. Gattrell, J. Park, B. MacDougall, J. Apte, S. McCarthy, C.W. Wu, J. Electrochem. Soc. 151 (2004) 123.

[20] D.M. Bernadi, M.W. Verbrugge, AIChE J. 37 (1991) 1151

[21] D.M. Bernadi, M.W. Verbrugge, J. Electrochem. Soc. 139 (1992) A2477.

[22] R.A. Freeze, J.A. Cherry, Groundwater, Prentice-Hall, New Jersey, 1979.

[23] R.F. Probstein, Physicochemical Hydrodynamics, Butterworth Publishers, MA 1989.

[24] T.E. Springer, T.A. Zawodinski, S. Gottesfeld, J. Electrochem. Soc. 138 (1991) A2334.

[25] R. Schlögl, Z. Phys. Chem. (Frankfurt) 3 (1955) 73

[26] S.G. Bratsch, J. Phys. Chem. Ref. Data 18 (1989) 1.

[27] I. Rubenstein, Physical Electrochemistry, Marcel Dekker, 1995.

[28] J. Healy, C. Hayden, T. Xie, K. Olson, R. Waldo, M. Brundage, H. Gasteiger, J. Abbot, Fuel Cells 5 (2005) 302.

[29] A.A. Shah, T.R. Ralph, F.C. Walsh, J. Electrochem. Soc. 156 (2009) B465

[30] A.B. LaConti, M. Hamdan, R.C. McDonald, in: A. Lamm, W. Vielstich, H. Gasteiger (Eds.), Handbook of Fuel Cells-Fundamentals, Technology and Applications, vol. 3, John Wiley \& Sons Inc, 2003, p. 647.

[31] T. Yamamura, M. Watanabe, T. Yano, Y. Shiokawa, J. Electrochem. Soc. 152 (2005) 830.

[32] R. Mills, Phys. Chem. 77 (1973) 685.

[33] M.W. Verbrugge, F. Hill, J. Electrochem. Soc. 137 (1990) 886.

[34] G.E. Zaikov, A.P. Iordanskii, S. Markin, Diffusion of Electrolytes in Polymers, VSP, Utrecht, Netherlands, 1988.

[35] J.C. Brown, Tappi J. 33 (1950) 130.

[36] J.L. Fales, E. Vandeborough, Electrochem. Soc. Proc. 86 (1986) 179

[37] C. Ziegler, A. Schmitz, M. Tranitz, E. Fontes, O. Schumacher, J. Electrochem. Soc. 151 (2004) A2028.

[38] A. Bard, R. Parsons, Jordan, Standard Potentials in Aqueous Solution, Marcel Dekker, New York, 1985.

[39] M. Pourbaix, Atlas of Electrochemical Equilibria in Aqueous Solutions, second ed., NACE International, Houston, 1974. 